\title{
Expansions in Maternity Leave Coverage and Children's Long-Term Outcomes
}

\author{
By Christian Dustmann and Uta SchönberG*
}

\begin{abstract}
This paper evaluates the impact of three major expansions in maternity leave coverage in Germany on children's long-run outcomes. To identify the causal impact of the reforms, we use a difference-indifference design that compares outcomes of children born shortly before and shortly after a change in maternity leave legislation in years of policy changes, and in years when no changes have taken place. We find no support for the hypothesis that the expansions in leave coverage improved children's outcomes, despite a strong impact on mothers' return to work behavior after childbirth. (JEL J13, J16, J22, J32)
\end{abstract}

ver past decades, many countries have witnessed a large increase in female labor force participation rates, with participation rates of mothers with young children increasing the most. In the United States, 20 percent of mothers with children under age 6 were working in 1960, but 60 percent of mothers with children under age 6 were working by 1990 (see e.g., Barrow 1999, Leibowitz and Klerman 1995). More than half of the mothers who are employed during pregnancy go back to work within three months after childbirth (Leibowitz, Klerman, and Waite 1992). This number is high by international standards. In the United Kingdom, Sweden, and Germany, less than 10 percent of previously employed mothers return to work so early (Gustaffson et al. 1996).

Countries have taken different avenues in the way they regulate the re-entry of mothers after childbirth, in the form of maternity leave legislation. While women in the United States are entitled to 12 weeks of unpaid leave, women in Germany are eligible to 3 years of job-protected leave. Currently, many of these regulations are under review. For instance, Canada increased paid family leave from 26 to 50 weeks in 2000. In 2003, California approved a policy that entitles women to up to six months of paid leave. Other US states, such as New Jersey, are considering implementing similar policies. Other countries that have recently expanded their leave coverage include the United Kingdom (2003, 2007) and Denmark (2002).

\footnotetext{
* Dustmann: Department of Economics, University College London, Gower Street, London WC1E 6BT, England (e-mail: c.dustmann@ucl.ac.uk); Schönberg: Department of Economics, University College London, Gower Street, London WC1E 6BT, England (e-mail: u.schoenberg@ucl.ac.uk). We would like to thank David Card, Ken Chay, Janet Currie, Larry Katz, Derek Neal, as well as seminar participants at Bocconi University, Brown University, the University of Chicago, the European Society of Population Economics (ESPE), University of Freiburg, Harvard University, Michigan State University, University of Munich, The University of British Columbia (UBC), and University College London (UCL) for constructive comments and suggestions. We thank Thomas Cornelissen for research assistance. All remaining errors are our own.

${ }^{\dagger}$ To comment on this article in the online discussion forum, or to view additional materials, visit the article page at http://dx.doi.org/10.1257/app.4.3.190.
} 
An important goal of the recent expansions in leave coverage around the world is to improve the welfare of children, and the expansions are explicitly aimed at increasing the time mothers spend with their infants after childbirth. This is motivated by an agreement among psychologists that the first months in a child's life are crucial for future cognitive and emotional development (see e.g., Harris 1983, and Lewis and Brooks-Gunn 1979). Arguments for why a delay in the return to work may benefit children include prolonged breastfeeding, as well as an increase in the quantity and quality of child-parent interactions. However, a delay in the return to work may also reduce other child-related investments, such as time spent with other family members or with professional child minders. Furthermore, a delay in the return to work may lower available household income, which is likely to have a detrimental impact on the child. The overall impact of early maternal employment, and thus of a prolonged leave period, on the child is therefore unclear.

In this paper, we evaluate the impact of three major expansions in leave coverage on children's long-term educational attainment. We find little support for the hypothesis that the expansions in leave coverage improved children's outcomes, although they had a strong impact on mothers' return to work behavior after childbirth. Given the precision of our baseline estimates, we are able to exclude that the expansion in paid leave from 2 to 6 months in 1979 increased children's average years of schooling by more than 6 days, and increased wages at the age of 28 by more than 0.3 percent. We are also able to rule out that the expansion in paid leave from 6 to 10 months in 1986 raised the probability of completing high track schools by more than 0.42 percentage points. The 1992 expansion in leave coverage may even have lowered children's educational attainment. Here, our point estimates suggest that the expansion reduced the probability that the child attends the high track (schools that streamline children for university) by about 0.6 percentage points. We offer two main explanations for this negative impact. First, in contrast to the earlier expansions in leave coverage, the expansion in unpaid leave from 18 to 36 months resulted in an income loss of 3,092 Deutschmarks (\$2,023, using the 1992 exchange rate, in 1992 prices). Second, while the earlier expansions reduced maternal employment during the first year of the child's life, the 1992 expansion lowered the probability that the mother is working during the second and third year of the child's life, when the child is between 18 and 36 months old. Our findings are consistent with the hypothesis that children older than 18 months benefit from the stimuli that care givers other than their mother provide.

What do these "intention-to-treat" estimates imply about the impact of early maternal employment on child outcomes? Under the assumption that the expansions in leave coverage affect children's outcomes only through a reduction in the mother's employment after childbirth, we can use the expansions in leave coverage as an instrument for early maternal employment. While our two stage least squares estimates based on the 1979 and 1986 expansions in leave coverage are closely centered around zero and not statistically significant, our two stage least squares estimates based on the 1992 expansion in leave coverage suggest that staying one extra month at home when the child is between 18 and 36 months old slightly reduces the child's educational attainment at age 14 . This is in contrast to many 
nonexperimental studies which conclude that maternal employment, in particular full-time work in the first year of the child's life, reduces children's academic success (e.g., Baum 2003; Bernal 2008; Belsky and Eggebeen 1991; Berger, Hill, and Waldfogel 2005; and James-Burdumy 2005)..$_{1}^{1}$

Our paper is closely related to the literature on the impact of maternity leave policies on child development. The findings of this literature are so far mixed. For instance, exploiting variation in leave coverage across Western-Europe or OECD countries and over time, Ruhm (2000) and Tanaka (2005) find that longer leave periods reduce infant and child death. In a series of papers, Baker and Milligan (2008, 2010) analyze an expansion in leave coverage from 25 to 50 weeks in Canada. They find little evidence that the reform affected children's health, motor-social, and cognitive development, or the family environment, up to age 3 . In a similar vein, Würtz-Rasmussen (2010) concludes that an expansion in leave coverage from 14 to 20 weeks in Denmark had no significant impact on children's long-term educational outcomes. In contrast, Rossin (2011) evaluates the impacts of unpaid maternity leave provisions of the 1993 Family and Medical Leave Act (FMLA) in the United States, and finds that maternity leave led to small increases in birth weight, decreases in the likelihood of a premature birth, and substantial decreases in infant mortality for children of college-educated and married mothers. Similarly, Liu and Nordstrom Skans (2011) report that an expansion in leave coverage from 12 to 15 months in Sweden improved the academic success of children to highly educated mothers, but not to low or medium educated mothers. In contrast, Carneiro, Løken, and Salvanes (2010) conclude that an expansion in unpaid and paid leave coverage in Norway improved the educational attainment primarily of children to mothers with low education.

We extend this literature on several dimensions. First, we evaluate the impact of a series of policy changes, rather than one expansion in leave coverage. This allows us to analyze whether such reforms have a different impact on child outcomes when they affect children in different age brackets, as well as the difference between paid and unpaid expansions in leave coverage on child outcomes. Second, we require substantially weaker assumptions for identification than many existing studies. Our identification strategy combines a discontinuity design with a difference-in- difference approach. We first compare outcomes of children born shortly (i.e., one month in our most stringent specification) before and after the reform. To isolate possible seasonal and age of school entry effects from those of the policy reform, we then use children born in the same months, but in years when no policy changes took place, as a control group. In contrast, also relying on a discontinuity approach, Baker and Milligan $(2008,2010)$ compare children born three years before and after the expansion in leave coverage, while Ruhm

\footnotetext{
${ }^{1}$ The few studies that use an experimental design to study the impact of maternal employment on the child typically exploit plausibly exogenous changes in maternal labor supply induced by the series of welfare reforms that were implemented in the United States during the mid-1990s (see e.g., Grogger, Karoly, and Klerman 2002; and Bernal and Keane 2010a; see also Smolensky and Gootman 2003, chapter 4, for a summary of these studies), and thus refer to a particular group of low-income mothers. An exception is Baker, Gruber, and Milligan (2008) who evaluate the impact of a generous child care subsidy in Quebec on child development up to age 4, using other Canadian provinces as a control group.
} 
(2000) and Tanaka (2005) make the identifying assumption that time trends are the same across European and OECD countries. Third, we analyze long-run educational outcomes of children, whereas most of the existing literature, such as Rossin (2011) and Baker and Milligan (2008, 2010), has focused on short-run effects of changes in leave coverage. ${ }^{2}$

The remainder of the paper is organized as follows. In Section I, we discuss the mechanisms through which early maternity employment, and thus expansions in leave coverage, can affect later outcomes of children. We also provide the necessary background information for our study, including a detailed description of the major changes in maternity leave legislation in Germany. Section II outlines our identification strategy. We describe the data in Section III. In Section IV, we first summarize the impact of the expansions in leave coverage on mothers' labor market outcomes, and then present intention-to-treat estimates of the impact of the expansions in leave coverage on children's educational success. Section V concludes.

\section{Background}

\section{A. Mechanisms: Expansions in Leave Coverage, and Child Development}

In our empirical analysis, we seek to estimate the "intention-to-treat" (ITT) impact of an expansion in leave coverage from $t_{1}$ to $t_{2}$ months on child outcomes (denoted by $Y$ ), which is the expected difference in child outcomes when the child is exposed to $t_{2}$ rather than $t_{1}$ months of maternity leave:

$$
\beta_{M L}^{I T T}=E\left[Y_{i} \mid M L=t_{2}\right]-E\left[Y_{i} \mid M L=t_{1}\right] .
$$

The primary goal of the expansions in leave coverage in Germany was to increase the time children spend with their mothers and to reduce the time children spend with alternative care givers after childbirth (see the discussion in Section IB). This will improve child outcomes if the return to time investments by the mother exceeds that by alternative care givers. Breastfeeding provides one explanation why, when the child is very young, this may be the case. The World Health Organization recommends exclusive breastfeeding for 6 months and breastfeeding complemented with other foods up to the age of 2 . Breastfeeding has been associated with protection against, for instance, diarrhea, asthma, sudden death syndrome, and leukemia, as well as with the enhancement of the child's cognitive development; see e.g., Ip et al. (2007) and León-Cava et al. (2002) for extensive evidence. At the same time, research shows that nonworking mothers breastfeed longer than working mothers, and that breastfeeding often stops when the mother returns to work (see e.g., Berger, Hill, and Waldfogel 2005; Lindberg 1996).

Attachment theory provides a second reason why, when children are very young, the marginal return to time investments by the mother may exceed that of alternative care givers. Psychologists generally agree that the relationships children form

\footnotetext{
${ }^{2}$ Exceptions are the papers by Würtz-Rasmussen (2010), Liu and Nordstrom Skans (2011) and Carneiro et al. (2011). Unlike us, these papers study a single reform only.
} 
with their mothers early on, in particular during the first year of their life, are critical for developing a sense of self, of others, and of trust, and are important to their future cognitive and social development (see for instance Bowlby 1969; Lewis and Brooks-Gunn 1979; Belsky 1988; and Belsky and Eggeben 1991)..$^{3}$ However, as children become older, they are likely to benefit from the exposure to other children and adults other than their mother. Thus, an expansion in maternity leave coverage from, say, 2 to 6 months, may have a more beneficial impact on the child's development than an expansion in leave coverage from, say, 18 months to 3 years.

In addition to time investments by mothers and alternative care givers, an expansion in maternity leave coverage may affect the mother's income, thereby affecting purchases for child goods and hence child development. ${ }^{4}$ A fully paid expansion in leave coverage is likely to have a smaller impact on mother's cumulative income than an unpaid expansion in leave coverage, and may hence have a more positive impact on the child's development.

Finally, an expansion in leave coverage may have additional secondary effects on child outcomes. The most important factor here is fertility. Lalive and Zweimüller (2009) show that an expansion in leave coverage from one to two years in Austria caused mothers to have their second child earlier, before the first born's second birthday. The reform also increased the probability of having at least one additional child within 10 years by about 3 percentage points. This may affect the intensity of attention the child gets during early childhood. Moreover, if fathers qualify for paternity leave, expansions in leave coverage may reduce father's labor supply after childbirth. ${ }^{5}$ The effects of these factors on the child's development are principally ambiguous.

Hence, although expansions in leave coverage around the world have typically been introduced to foster child development, different types of reforms affecting the child at different stages of their development may have different, and even detrimental, long-term effects. In particular, we expect a partially paid expansion in leave coverage in the first year of the child's life (like the expansion in leave coverage from 2 to 6 months in 1979) to have a more beneficial effect on child development than an unpaid expansion in leave coverage in the third year of the child's life (like the expansion in leave coverage from 18 to 36 months in 1992).

\section{B. Maternity Leave Legislation in Germany}

In the United States, the FMLA introduced in 1993 requires firms with at least 50 employees to provide 12 weeks of unpaid leave after childbirth. In Germany,

\footnotetext{
${ }^{3}$ In addition to the child's age, the marginal returns of time investments of alternative care givers depend on the type and quality of child care arrangements. Most of the literature on child care usage focuses on child care centers (e.g., Magnuson, Ruhm, and Waldfogel 2007; Baker, Gruber, and Milligan 2008) or on particular programs designed to boost educational outcomes of disadvantaged children, such as Head Start (e.g., Currie and Thomas 1995, 1999; Garces, Thomas, and Currie 2002). Baydar and Brooks-Gunn (1991) is one of the few studies that explicitly analyzes the effect of grandparent care on child development.

${ }^{4}$ Note that a decline in mother's income may not only lower total household income, but also worsen her bargaining position within the household. Studies by for instance Murnane, Maynard, and Ohls (1981) and Phipps and Burton (1998) have found that this may lead to lower investments into the child.

${ }^{5}$ In Germany, fathers are eligible for leave taking since 1986. However, few fathers take leave (less than 1.5 percent in 1992; see Vaskovics and Rost 1999 for a detailed study), so that this effect is likely to be small.
} 


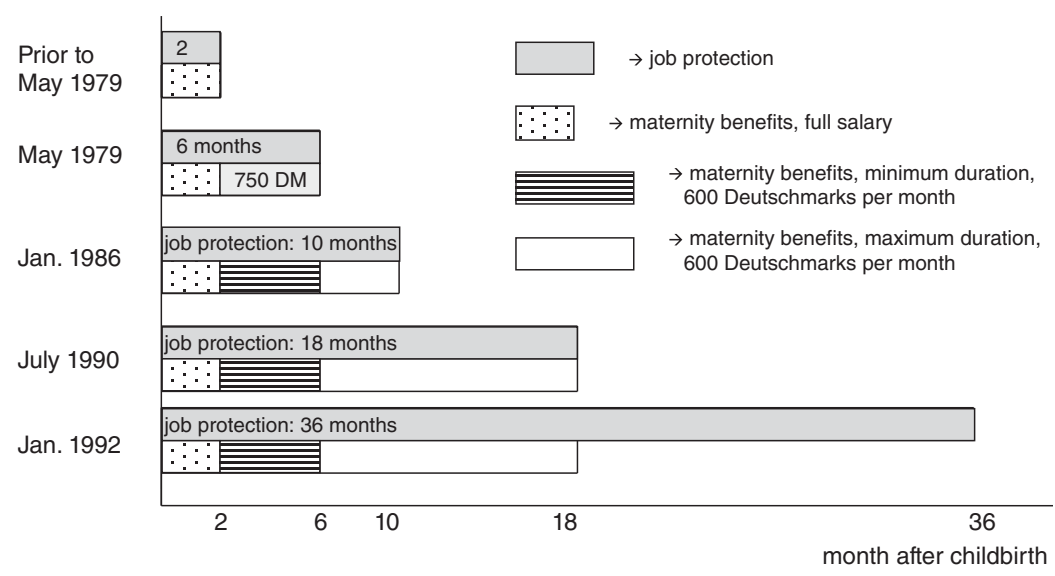

Figure 1. Maternity Leave Legislation in Germany (Selected Reforms)

Notes: Since 1986, all women, employed before childbirth or not, are entitled to a maternity benefit of 600 Deutschmarks per month for a minimum of 6 months. From the seventh month onward, maternity benefits are means-tested, and depend on the annual net family income two years before childbirth. In January 1988, maternity leave was extended from 10 to 12 months. Two further changes occurred in July 1989 and July 1990, when maternity leave was increased to 15 and 18 months, respectively.

mothers have been entitled to paid leave 6 weeks before and 8 weeks after childbirth since the mid-1950s. During the leave period, the firm is not allowed to dismiss the mother, and the mother has the right to return to a job that is comparable to the job she held before childbirth. Payment during this period is equivalent to her average income over the three months prior to childbirth.

Starting in the late 1970s, Germany experienced a series of unexpected expansions in leave coverage. Figure 1 provides a visual overview of the main reforms. The first reform took place in May 1979 when job-protected leave after childbirth was raised from eight weeks to six months. The primary motivation behind this reform was the health of the mother, although the potential benefits that the expansion may have on the welfare of the child were also recognized (Gesetzentwurf der Bundesregierung, Drucksache 8/2613). Payment between six weeks before and eight weeks after childbirth remained unchanged from the mother's average income over the three months prior to childbirth. From the third month after childbirth onward, payment was 750 Deutschmarks per month (about one-third of average pre-birth earnings in 1979). Only women who were employed before childbirth were entitled to maternity benefits.

The later expansions in leave coverage that took place between the mid-1980s and early 1990s shifted the focus from the health of the mother to the welfare of the child. These reforms were motivated by the agreement among psychologists that the first months and years are the most important in a child's life, and were explicitly aimed at encouraging mothers to spend more time with their child after childbirth (Gesetzentwurf der Bundesregierung, Drucksache 10/3792).

The 1986 reform increased the job-protection period from 6 months to 10 months, and announced a further increase to 12 months starting in January 1988. An 
important component of this reform was that all mothers, regardless of their employment status before childbirth, became eligible for maternity benefits. A further component was that fathers became eligible for paternity leave. Maternity payment from 6 weeks before to 8 weeks after childbirth remained once again unchanged from the mother's income prior to childbirth (or about 600 Deutschmarks per month ${ }^{6}$ if the mother was not working before childbirth). From the third to the sixth month after childbirth, maternity benefits were equal to 600 Deutschmarks, independent of the mother's (and father's) income prior to childbirth. This corresponds to about 20 percent of average pre-birth earnings in 1986. From the seventh month onward, maternity benefits were means-tested, depending on the annual net family income during the two years before childbirth.

In July 1989 and July 1990, job-protected leave was further lengthened to 15 and 18 months, respectively. The final policy reform took place in January 1992, when job-protected leave was increased from 18 to 36 months. Maternity payments still ended at 18 months, but were to be extended to 24 months one year later, in January 1993.

Our empirical analysis focuses on the impact of the three major policy changes in 1979, 1986, and 1992. We do not consider the 1989 and 1993 reforms as these were announced at least one year prior to their introduction when the previous reform came into effect. We also discard the smaller changes in maternity leave legislation in July 1989 and July 1990 because their introduction coincides with the cut-off age for school entry. In Germany, children born in July usually start school a year later than children born in June, making it difficult to isolate the effect of age at school entry on educational and labor market outcomes from that of the policy reform.

For the first reform we consider (May 1, 1979), the government proposed a draft bill on January 5, 1979. This bill was ratified by the Upper House of the German Parliament on May 10 and by the Lower House on June 22, 1979. All mothers who gave birth on or after May 1, 1979, and whose maternity leave period ran out (at the earliest) on June 30, 1979, could apply for a total maternity leave of six (rather than 2) months. For the second reform we consider (January 1, 1986), the draft bill was proposed on August 161985 and ratified on November 14 and November 29, 1985 by the Upper and Lower House, respectively. For the third reform (January 1, 1992), the draft bill was proposed on August 16, 1991 and ratified by the Upper and Lower House on November 7, and November 11, 1991, respectively. It is important to note that the draft bill for all the three reforms was introduced long after the conception period for births at the reform date.

\section{Identification Strategy}

To estimate the "intention-to-treat" effect of an expansion in leave coverage on child outcomes, $\beta_{M L}^{I T T}$, given by equation (1) in Section IA, we use a difference-in-difference design that compares outcomes of children born shortly

\footnotetext{
${ }^{6}$ This corresponds to about US $\$ 400$ per month, using the 1992 Deutschmarks-dollar exchange rate.
} 
before and shortly after a change in maternity leave legislation (i.e., children born within one month of the expansion in our most stringent specification, and within six months in our widest specification) in years of policy changes, and years when no changes have taken place. A similar strategy has, for instance, been used by Lalive and Zweimüller (2009) and Lalive et al. (2010) to evaluate the impact of an Austrian policy reform on mothers' fertility and labor market outcomes, and by Ekberg, Eriksson, and Friebel (2005) to analyze the impact of Sweden's "daddy month reform" on the labor supply of fathers.

This identification strategy would not be valid if women time the birth of their child as a response to the change in maternity leave legislation. This seems unlikely, since women could not precisely anticipate these reforms. As we explain in Section IB, the draft bills for all three reforms we consider here were proposed after the children born within six months of the reform date were conceived. However, some discussion on these bills may have been in the public domain before the draft bills were proposed. We searched two leading German newspapers ${ }^{7}$ for articles about the reform. The first articles typically appear no more than two months before the reform was finally implemented.

Women may still have some possibilities to time the birth of their child through induced births or cesarean sections. ${ }^{8}$ This allows women to mostly bring the birth date forward, whereas, in our case, they would like to postpone childbirth in order to become eligible for the more generous leave policy. However, Gans and Leigh (2009) provide empirical evidence that women also have some possibilities to delay childbirth. They found that the introduction of a \$3,000 "Baby Bonus" in July 1, 2004 in Australia led to a sharp drop in the number of births just before, and to a sharp increase just after, the policy commenced, although the policy was announced only seven weeks before its introduction. In order to deal with this concern, we have analyzed the evolution of the number of births during the days and weeks surrounding the policy expansion in 1992, and found little evidence that the expansion affected the timing of births around the reform (results are available on request). 9 As a further robustness check, we also exclude children who were born just before or after the reform, i.e., children whose birthdays are most likely to be affected by the reform.

A simple comparison between children born shortly before and after an expansion in leave coverage will lead to a biased estimate of the causal impact of the reform if birth month affects child outcomes directly. Some studies document surprisingly large seasonal effects, with children born in spring generally doing better than children born in winter; see e.g., Buckles and Hungerman (2008) for a recent

\footnotetext{
${ }^{7}$ The search was conducted using Süddeutsche Zeitung and Frankfurter Allgemeine.

${ }^{8}$ Dickert-Conlin and Chandra (1999) find that in the United States tax benefits increase the probability that a child is born in the last week of December rather than the first week of January, partly because of the use of cesarean sections.

${ }^{9}$ We cannot analyze the evolution of births surrounding the other policy reforms because data on the number of births per day is currently available only from 1991 onward. We would expect the timing of births to be more important for the 1992 reform than for the 1979 and 1986 reforms, due to the increase in cesarean sections over this time period. Note that even in 1992, only 15.9 percent of births (compared to 22.3 percent in the US) were cesarean sections, which is close to the share considered unavoidable for medical reasons. Hickl and Franzki (2002) report that in about 10 percent of all births, a cesarian is necessary to save the life or health of mother or child.
} 
analysis. Even more importantly, children born after the reform are, on average, younger at school entry than children born before the reform. ${ }^{10}$ In order to isolate the causal impact of the policy reform from age of school entry and seasonal effects, we adopt a difference-in-difference approach and use children born in the same months, but in a year in which no reform took place, as a control group. The key assumption here is that the seasonal and age of school entry effects are the same for the treated and the control cohorts. An important advantage of this approach is that we do not need to assume a particular functional form for the seasonal and age of school entry effect. In fact, the difference-in-difference approach allows us to specify the function in a fully flexible manner, by including a full set of birth month dummies in our regression. For robustness, we also provide estimates based on a regression discontinuity approach that assumes a particular functional form for the seasonal and age of school entry effects (see Section IVB).

We estimate regressions of the following type, separately for each expansion in maternity leave coverage (which we denote by the superscript $M L$ ):

$$
\begin{aligned}
\text { Outcome }_{i, m}= & \alpha_{o}+\alpha_{1} \text { Treat }_{i, m}+\alpha_{2} \text { After }_{i, m}+\alpha_{3} \text { Treat }_{i, m} \cdot \text { After }_{i, m} \\
& +\sum_{m} \theta_{m} D_{i, m}+v_{i, m},
\end{aligned}
$$

where $i$ and $m$ are indicators for child $i$ and birth-month $m$. Treat $t_{i, m}$ is an indicator variable equal to one if child $i$ born in month $m$ belongs to the "treated" cohort that was affected by the reform in maternity leave legislation (referring to children born between July 1991 and June 1992 in our widest specification). After ${ }_{i, m}$ is an indicator variable equal to one if the child is born in the months just after the reform came into effect (referring to children born in January to June). Treat $_{i, m} \cdot$ After $_{i, m}$ is the interaction between these two variables (referring to children born between January and June 1992), and $D_{i, m}$ is a dummy variable equal to one if the child was born in month $m .{ }^{11}$ The coefficient of interest is $\alpha_{3}^{M L}$, which identifies the intention-to-treat effect of the expansion in maternity leave legislation on child outcomes and corresponds to $\beta_{M L}^{I T T}$ in equation (1). We first estimate regression (2) using children born one month before and after the policy reform (and children born in the same months in years in which no reform took place as a control group). To gain precision, we then increase the estimation sample and include children born two, three, and up to six months before and after the reform.

\section{Data and Outcome Variables}

Our empirical analysis on children combines an administrative dataset on educational outcomes with an administrative dataset on school choices. Our analysis on

\footnotetext{
${ }^{10}$ See e.g., Bedard and Dhuey (2006) for international evidence. In Germany, children who are born in July typically start school a year later than children born in June.

${ }^{11}$ Of course, since we include a dummy variable indicating that the child was born after the reform came into effect $\left(\right.$ After $\left._{i, m}\right)$, we have to exclude two birth month dummies to avoid perfect collinearity. We exclude the birth months immediately surrounding the reform (i.e., January and December).
} 
the labor market responses of mothers to the expansions in leave coverage is based on an administrative dataset covering mothers' entire work histories. We describe each dataset in turn. Since some of the foreign children were not born in Germany, and were thus not affected by the expansions in leave coverage, we restrict the sample to children and mothers who are German citizens.

\section{A. Administrative Data on School Choices (Children)}

Our first dataset covers all students attending public schools in three German states: Hesse, Bavaria, and Schleswig-Holstein. We use this dataset to evaluate the impact of the expansions in leave coverage from 6 to 10 months in 1986 and 18 to 36 months in 1992 on children's outcomes. The dataset is available for the academic school years 2002-2003 to 2008-2009 for the states of Hesse and SchleswigHolstein, and for the school years 2004-2005 to 2008-2009 for Bavaria. An important advantage of our data, crucial for our research design, is its large sample size. For each birth month, we observe at least 15,000 children.

For the 1992 policy reform, our outcome variable is the type of school attended at age 14 when most children attend eighth grade. Germany tracks children into three main types of schools after fourth grade. The least academic track is called Hauptschule (grades 5-9), the medium track is called Realschule (grades 5-10), and the most academic track is called Gymnasium (grades 5-13). ${ }^{12}$ In our sample, 29.4 percent of pupils attend the low track, 35.2 percent attended the medium track, and 35.4 percent attendedthe high track. Only graduation from the high track provides direct access to university or college education. The low and medium tracks are designed to prepare students for vocational training within the German apprenticeship system.

In neither state is there a strict entry requirement (such as an entry exam) that determines which pupils are allowed to attend the higher tracks. In all three states, track choice depends crucially on teacher recommendations, although in Hesse and Schleswig-Holstein, parents have the final word which track their child attends. In Bavaria, pupils have to fulfill a requirement concerning school marks or otherwise pass a special test if their parents want to deviate from the teacher committee's recommendation. ${ }^{13}$ Thus, the track in which we observe children can be viewed as the discrete outcome of some underlying and unobserved continuous performance measure, which in turn may be affected by changes in maternity leave legislation.

Table 1 illustrates the usefulness of track choice as an outcome variable. In columns 1 and 2, we regress reading and math test scores on indicators of whether the student attends the medium or high track school, with the low track school as the omitted category. The data comes from the German part of the international PISA survey of 15-year-olds for the years 2003 and 2006. Track choice alone can

\footnotetext{
${ }^{12}$ In all three states, there exists a fourth comprehensive school type that comprises all three track choices (Gesamtschule). We categorize pupils in these schools as in the medium track. There are also schools for children with special needs (Sonderschule), ranging from schools for pupils with down syndrome, to schools for the deaf and blind, to, most importantly, schools for pupils with learning disabilities and severe behavioral problems. In our sample, only 3.7 percent of pupils attend special need schools. We categorize these pupils as in the low track.

${ }^{13}$ Information retrieved from http://www.kmk.org/doc/publ/ueberg.pdf on November 27, 2008.
} 
Table $1-$ Track Choice and Test Scores

\begin{tabular}{|c|c|c|c|}
\hline & \multicolumn{2}{|c|}{ Test scores (PISA) } & \multirow[b]{2}{*}{$\begin{array}{c}\text { Log-wages (GSOEP) } \\
\text { (3) }\end{array}$} \\
\hline & $\begin{array}{l}\text { Reading score } \\
\text { (1) }\end{array}$ & $\begin{array}{l}\text { Mathematics score } \\
(2)\end{array}$ & \\
\hline Medium & $\begin{array}{l}0.656 \\
(0.057) * * *\end{array}$ & $\begin{array}{l}0.626 \\
(0.059) * * *\end{array}$ & $\begin{array}{l}0.238 \\
(0.005) * * *\end{array}$ \\
\hline High & $\begin{array}{l}1.541 \\
(0.052) * * *\end{array}$ & $\begin{array}{l}1.640 \\
(0.059) * * *\end{array}$ & $\begin{array}{l}0.494 \\
(0.005) * * *\end{array}$ \\
\hline $\begin{array}{l}\text { Adj. } R^{2} \\
\text { Observations }\end{array}$ & $\begin{array}{l}0.340 \\
6.942\end{array}$ & $\begin{array}{l}0.388 \\
6.942\end{array}$ & $\begin{array}{c}0.347 \\
31.175\end{array}$ \\
\hline
\end{tabular}

Notes: In columns 1 and 2, we regress reading and mathematics test scores on track choice in grade 9. The sample refers to German pupils attending ninth grade in 2003 or 2006. The lowtrack choice is the omitted category. Regressions additionally control for a year fixed effect. For each area of assessment, PISA provides five measures of proficiency. They are five random draws from the probability distribution of the student's proficiency, which PISA estimates from the share of each student's correct answers and from the difficulty of the questions that the student answered. We follow the procedure proposed in the PISA Technical Report (2006) to obtain unbiased coefficients and standard errors. In column 3, we regress the log real hourly wage on track completion. Here, the sample is based on the years 1984 to 1998, and includes employed men and women between ages 21 and 65. Regressions condition on age (polynomial of order 3), gender, and year fixed effects.

*** Significant at the 1 percent level.

** Significant at the 5 percent level.

* Significant at the 10 percent level.

Source: Columns 1 and 2: PISA, 2003 and 2006. Column 3: GSOEP for men and women between 21 and 65 years of age, 1984-1998.

explain 34 percent and 38.8 percent of the variation in reading and mathematics test scores. Average reading and mathematics test scores at the high track are 1.54 and 1.64 standard deviations higher than at the low track.

For the 1986 policy reform, our outcome variable is graduation from the high track by age 20. This allows for one extra year to finish the high track, due to either delayed school entry or grade repetition. High track graduation is an important outcome variable. When we regress individuals' wages on the track the individuals graduated from, using data from the German Socioeconomic Panel, the results in Table 1 (column 3) show that men and women graduating from the high track earn 49 percent (in log points) higher wages than men and women graduating from the low track. ${ }^{14}$

Unfortunately, most children born around the 1986 policy reform would attend eleventh (Hesse and Schleswig-Holstein) or thirteenth grade (Bavaria) in the first year we observe them in our data. Hence, since the minimum schooling requirement in Germany is nine years, some students have left school already and are thus no longer in our dataset. To compute graduation rates, we therefore combine the information in our data on the number of pupils who are still enrolled in high school with information on all recorded births in each state. We then proxy graduation from the high track as the ratio between the number of students ever observed in thirteenth grade and the number of recorded births. See Appendix A for additional information.

\footnotetext{
${ }^{14}$ See Dustmann (2004) for similar evidence.
} 


\section{B. Administrative Data on Education and Labor Market Outcomes (Children)}

Our second data source comes from social security records provided by the Institute for Labor Market Research in Nuremberg (IAB), and is available for the years 1975-2008. The data allow us to construct the complete work history of every man and woman covered by the social security system. Not included in the data are civil servants, military personnel, and the self employed. We use this data to analyze the impact of the expansion in leave coverage in 1979 from two months to six months on children's outcomes, and hence select all (West) German citizens born between three years before and one year after the reform. By the end of our sample, these individuals are between 28 and 32 years old. As before, the main advantage of these data is a large sample size. For each birth month, we observe at least 42,000 men and women.

While at any point in time only about 80 percent of the workforce is covered by the social security system (e.g., Bundesagentur für Arbeit 2004), the vast majority held a job covered by the social security system before the age of 28 , and is hence included in our sample. Our first outcome variable is the highest educational achievement by age 29 or 28 , respectively. We distinguish three different categories: individuals without any post-secondary education, ${ }^{15}$ individuals who completed an apprenticeship, and individuals with a (five-year) university or (four-year) college degree. We refer to these three choices as low-skilled, medium-skilled, and highskilled. Based on the individuals' educational choices, we also compute a variable "years of schooling," assigning 16 years of schooling to low-skilled individuals, 19 or 21 years of schooling to medium-skilled individuals, depending on whether or not they graduated from the high track, and 24 or 25 years of schooling to high-skilled individuals, depending on whether they completed a college or a university degree. Our second outcome variable is the wage earned at age 28 or 29, respectively. Here, we restrict the sample to individuals who are employed full time at age 28 or 29 , respectively. In order to check whether the expansions in maternity leave coverage affected selection into full-time work, we use an indicator variable that is equal to one if the individual is employed full-time as a third outcome variable.

\section{Administrative Data on Labor Market Outcomes (Mothers)}

Our data on labor market outcomes of mothers affected by the expansions in leave coverage come from the same data source as our data on educational attainment of children affected by the expansion in leave coverage in 1979, social security records for the years 1975-2008. To study the impact of the expansions in leave coverage on mothers' labor market outcomes, we select all West German women who signed up for maternity leave between 1976 and 1995 and who are between 16 and 45 years of age. An important advantage of this data is once again its large sample size. In our final sample, there are at least 13,000 women who go on maternity

\footnotetext{
${ }^{15}$ This category includes individuals with unknown education.
} 
leave each month. In addition, the data contain precise information on mothers' labor supply, allowing us to determine the exact month the mother returns to work after childbirth. However, our data also have one important shortcoming; they do not contain direct information on children. Hence, we only have information on mothers who take maternity leave, and not on all mothers who give birth. In order to determine the share of mothers who go on maternity leave, we rely on an additional data source, the IABS 75-95 Plus. See Schönberg (2009) for a detailed description of this dataset.

Moreover, the lack of direct information on children implies that we have to infer the birth month of the child from the month the mother goes on leave, which is likely to lead to some measurement error. Based on the IABS 75-95 Plus, Schönberg (2009) shows that the imputed birth month of the child is correctly measured for about 70 percent of children, and over- or underestimated by one month for about 25 percent of children. This type of measurement error implies that some women whom we record giving birth just before a change in maternity leave legislation (e.g., in December 1991) have in fact given birth after the change (e.g., in January 1992), and vice versa. Here, we deal with this problem by excluding mothers who give birth (and have taken some maternity leave) one month before or after the expansion in leave coverage. This exclusion ensures that we assign the correct maternity leave policy for more than 95 percent of mothers. See Schönberg and Ludsteck (2011) for more information.

We focus on the following outcome variables: the share of mothers who returned to work for at least two consecutive months by month $t$ after childbirth; the total number of months worked 40 months after childbirth; and the cumulative income (including maternity benefits) up until 40 months after childbirth.

\section{Analysis}

We first report the impact of the reforms on mothers' labor market outcomes (Section IVA). We then turn to intention-to-treat estimates of the impact of expansions in leave coverage on children's long-term outcomes (Section IVB). We offer a possible interpretation of our findings in Section IVC.

\section{A. Expansions in Leave Coverage and Mothers' Labor Market Outcomes}

Recall from Section IIIC that our data on mothers' labor market outcomes allow us to identify mothers who sign up for maternity leave only, and not all women who give birth. We therefore begin the empirical analysis by providing information on the share of mothers who take maternity leave (Figure 2). We first approximate this share as the ratio between the number of all births to German citizens and the number of women on maternity leave in our data (solid line). There is a clear upward trend in leave taking. The share increased from 31.53 percent in 1977 to 44.21 percent in 1993. These numbers are likely to underestimate the incidence of leave taking, as our data excludes up to 20 percent of the German workforce. We provide a more reliable estimate based on an additional data source, the IABS 75-95 Plus (dashed line). As expected, this data source reveals an almost 8 percentage point 


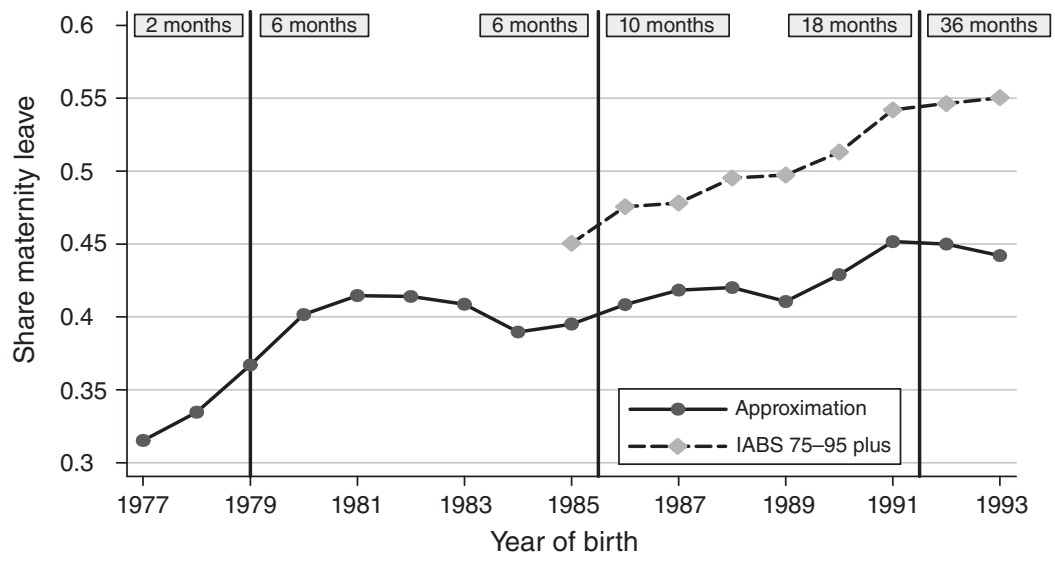

Figure 2. Maternity Leave Take-Up over Time

Notes: The solid line approximates the share of mothers who sign up for maternity leave as the number of women on leave in our data divided by the number of births in that year. This measure is best interpreted as a lower bound for the true share as our data cover only 80 percent of the German workforce. The dashed line provides a more reliable estimate of the share of mothers who sign up for maternity leave based on the IABS 75-95 Plus. Vertical lines indicate the three expansions in leave coverage which we analyze in this paper.

Data Sources: Solid line: IAB Social Security Data combined with Vital Statistics, 1977-1994. Dashed Line: IABS 75-95 Plus, 1986-1994.

Panel A. Expansion from 2 to 6 months (May 1979)

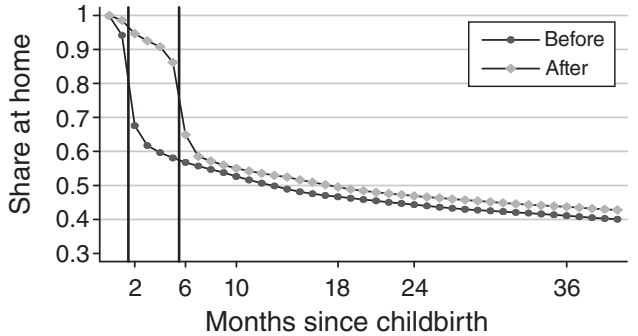

Panel C. Expansion from 18 to 36 months (January 1992)

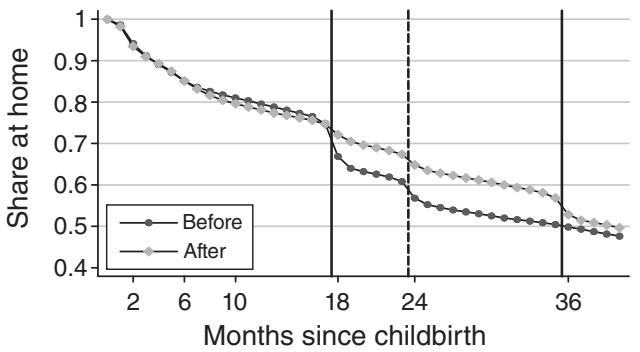

Panel B. Expansion from 6 to 10 months (January 1986)

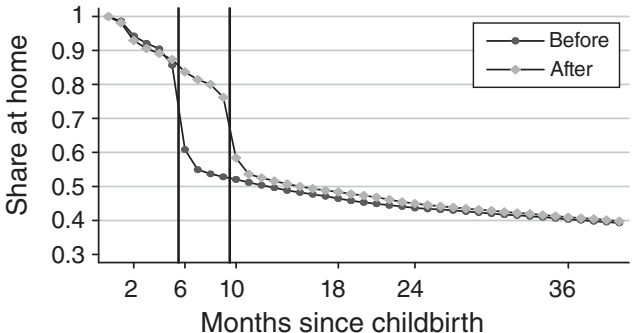

Figure 3. Expansions in Leave Coverage and Mothers' Return to the Labor Market

Notes: The figures plot the share of mothers who have not returned to the labor market $t$ months after childbirth, for mothers who give birth within six months of an expansion in leave coverage and go on maternity leave. Due to measurement error in the birth month, we exclude mothers who give birth one month before or one month after the expansion. The vertical lines indicate the end of the maternity leave period.

Source: Social Security Records on women who give birth between February and July 1979 (panel A), between October 1985 and March 1986 (panel B), and October 1991 and March 1992 (panel C) and who go on maternity leave. 
Table 2-Expansions in Leave Coverage, Early Maternal Employment, ANd CUMulative INCOME AFTer ChILdBIRTH

\begin{tabular}{|c|c|c|c|}
\hline & & Number of months away from work & Available income \\
\hline \multicolumn{4}{|c|}{ Panel A. 2 versus 6 months (May 1979) November-October, excl. April and May } \\
\hline (1) & all & $\begin{array}{l}0.835 \\
(0.093) * * *\end{array}$ & $\begin{array}{l}1,713.59 \\
(275.69) * * *\end{array}$ \\
\hline \multirow[t]{3}{*}{ (2) } & low wage & $\begin{array}{l}0.665 \\
(0.160) * * *\end{array}$ & $\begin{array}{l}2,852.34 \\
(306.14) * * *\end{array}$ \\
\hline & medium wage & $\begin{array}{l}0.899 \\
(0.161) * * *\end{array}$ & $\begin{array}{l}1,727.75 \\
(430.99) * * *\end{array}$ \\
\hline & high wage & $\begin{array}{l}0.911 \\
(0.164) * * *\end{array}$ & $\begin{array}{l}1,056.59 \\
(594.13) * * *\end{array}$ \\
\hline (3) & $p$-value & 0.477 & 0.009 \\
\hline
\end{tabular}

Number of months away from work

Cumulative income

Panel B. 6 versus 10 months (January 1986) September-June, excl. December and January

(1)

all

1.390

$-1,299.15$

(2)

low wage

$(0.167)^{* * * *}$

medium wage

1.563

$(0.278) * * *$

1.417

$(0.286) * * *$

high wage

1.187

$(0.308) * * *$

$p$-value

0.662

(535.51)**

$-958.99$

(557.73)*

$-1,112.56$

(802.77)

$-1,164.31$

$(1,263.61)$

(3)

Number of months away from work

0.981

Number of months away from work

Panel C. 18 versus 36 months (January 1992) July-June, excl. December and January

(1)

(2)

$$
\text { all }
$$

low wage

medium wage

high wage

(3)

$p$-value
1.363

$(0.106) * * *$

1.358

$(0.177) * * *$

1.368

$(0.177)^{* * * *}$

1.489

$(0.195) * * *$

0.862

Cumulative income

Notes: In each panel, we report difference-in-difference estimates of the impact of the expansions in leave coverage on the number of months away from work in the first 40 months since childbirth (column 1) and the cumulative income obtained up until the child is 40 months old (column 2). Cumulative income is defined as the sum of mothers' monthly income, including maternity benefits. We first report the average impact (row 1), and then report effects separately for mothers in the bottom, middle, and top third of the wage distribution prior to childbirth (row 2). In row 3 , we display the $p$-value for the hypothesis that the effect of the expansions in leave coverage is the same across all groups. In panel A, the treatment group consists of mothers who give birth between two and six months before or after the policy reform (i.e., between November 1978 to October 1979 excluding April and May). The control group consists of mothers giving birth in the same months, but one or two years before or one year after the policy reform. In panel B, the treatment group consists of mothers who give birth between two and four months before and between two and six months after the policy reform (i.e., between September 1985 and June 1986, excluding December and January). The control group comprises all mothers who give birth in the same months, but one or three years after the policy reform. In panel $\mathrm{C}$, the treatment group consists of all mothers who give birth between two to six months before or after the policy reform (i.e., between July 1991 and June 1992, excluding December and January). The control group includes mothers who give birth in the same months, but one year before or two or three years after the expansion in leave coverage. Robust standard errors in parentheses.

*** Significant at the 1 percent level.

** Significant at the 5 percent level.

* Significant at the 10 percent level.

Source: Social Security Records on women who give birth and sign up for maternity leave between November 1976 and October 1980 (panel A), between September 1985 and June 1989 (panel B), and between July 1990 and June 1995 (panel C). 
higher incidence of leave taking. The following figure and table in this section (i.e., Figure 3 and (Table 2) refers to mothers who sign up for maternity leave only.

In Figure 3, we plot the share of women who have not yet returned to work $t$ months after childbirth, separately for women who give birth between two and six months before or between two and six months after the reform. In each panel, the solid vertical lines refer to the length of the maternity leave period before and after the expansion in leave coverage (e.g., two months and six months for the 1979 expansion in leave coverage in panel A). The figure shows that for each policy reform, a large fraction of mothers return to the labor market at the end of the leave period, i.e., 2, 6, 10, 18, or 36 months after childbirth. ${ }^{16}$ This effect is considerably stronger for the shorter leave periods of 2, 6, or 10 months in panels A and B than for the longer leave periods of 18 and 36 months in panel C. The figure also shows that despite the considerable effect on mothers' labor supply in the short-run, the expansions had only a small effect on the overall share of women who returned to the labor market in the long run, after the job protection period has expired. Hence, the expansion in leave coverage from two to six months and six to ten months reduced maternal employment primarily during the first year of the child's life, between the second and sixth month and the sixth and tenth month after childbirth, respectively. The expansion in leave coverage from 18 to 36 months, in contrast, primarily lowered maternal employment during the second and third year of the child's life, between the eighteenth and thirty-sixth month after childbirth.

We provide more details in Table 2, where we report, in row 1, difference-indifference estimates based on equation (2) in Section II. Our sample includes mothers who give birth six months before (four months for the 1986 expansion, see Section IVB for an explanation) and six months after the policy reform. Due to measurement error in the month of birth, we exclude mothers who give birth one month before or one month after the expansion in leave coverage. We use mothers who give birth in the same months, but up to two years before or one year after the expansion as our control group. ${ }^{17}$ In the first column, our dependent variable is the number of months the mother has stayed away from work since childbirth by the time her child is 40 months old. ${ }^{18}$ The 1979 expansion in leave coverage from two to six months caused mothers to reduce their labor supply, on average, by 0.835 months, compared to 1.390 and 1.363 months for the 1986 expansion in leave coverage from 6 to 10 months and the 1992 expansion in leave coverage from 18 to 36 months, respectively. To put these numbers into perspective, Lalive et al. (2011) report that the expansion in leave coverage from 1 to 2 years in Austria decreased maternal employment in the first 5 years after childbirth by 3.2 months. Scaling our estimates to 1 year of leave coverage, we find roughly similar effects for the 1979 and 1986 expansions: 2.5 months for the first reform and 4.17 months for the second

\footnotetext{
${ }^{16}$ Notice that for the 1992 expansion in leave coverage, we also observe a large fraction of women returning to work 22 months after childbirth (the dashed vertical line in panel C). This is because Bavaria (which makes up roughly half of our sample) pays a maternity benefit of 500 Deutschmarks per month for an additional four months, up until the child is 22 months old.

${ }^{17}$ Our results are similar and not statistically different from each other for alternative specifications.

${ }^{18} \mathrm{We}$ find similar results when we use the number of months worked since childbirth by the time the child is 50 , 60 , or 80 months old as a dependent variable.
} 
reform. The scaled effect of the 1992 expansion in leave coverage (which increased the leave period by 18 months) is, however, considerably smaller, just below one month. One explanation for this discrepancy is that unlike the 1992 reform, the Austrian reform provided strong financial incentives to have a second child before the first child's second birthday. Lalive and Zweimüller (2009) find that these incentives led to a strong bunching of children and increased total subsequent fertility, and, hence, to a strong reduction in early maternal employment.

In the second column of Table 2, we report the impact of the expansions in leave coverage on mothers' cumulative income, which we compute as the sum of her monthly income up until her child is 40 months old. Monthly income is defined as her monthly earnings if the mother is working, as the monthly maternity benefit if she is not working but eligible for paid leave, and zero otherwise. We deflate monthly income by the consumer price index using 1992 as our base year so that numbers are in 1992 prices. The 1979 reform was partially pay-compensated, and increased mother's available income by about 1,700 Deutschmarks. ${ }^{19}$ The 1986 expansion, in contrast, lowered the mother's available income 40 months after childbirth by about 1,300 Deutschmarks, suggesting that among mothers who went on leave, the monthly maternity benefit of 600 Deutschmarks was not sufficient to fully compensate them for the earnings loss due to the delay in the return to work. Recall, however, that this reform also entitled mothers to maternity benefits who did not take a leave of absence from their employer. These mothers receive 600 Deutschmarks for the first 10 months after childbirth. As roughly 50 percent of mothers around the 1986 policy reform took a leave of absence from their employer (see Figure 2), the reform also had a slight positive impact on mothers' available income on average. The expansion in unpaid leave from 18 to 36 months in 1992, in contrast, lowered mothers' available income 40 months after childbirth by 3,092 Deutschmarks.

In order to interpret the impact of expansions on leave coverage on children's outcomes, it is important to understand which mothers are affected by the reform. In row 2 of Table 2, we report the impact of the expansions in leave coverage on maternal employment and cumulative income separately for mothers in the bottom, middle, and top third of the wage distribution prior to childbirth. The reforms reduced maternal employment by roughly the same amount for all three types of mothers. There is, however, some evidence that the 1979 expansion in leave coverage increased cumulative income predominantly for low-wage mothers, while the 1992 expansion in leave coverage decreased cumulative income predominantly for high-wage mothers.

To sum up, the primary effect of an expansion in leave coverage from month $t_{1}$ to $t_{2}$ is a short-run reduction in maternal employment between month $t_{1}$ and $t_{2}$ after childbirth. Neither reform had a strong impact on maternal employment in the longrun, after the expiration of the leave period. While the partially paid expansions in leave coverage from 2 to 6 months and from 6 to 10 months slightly increased

\footnotetext{
${ }^{19}$ The partially pay-compensated reform has two effects on average available income. First, the reform reduced maternal employment from month two to six after child birth. For this group, the reform decreased available income. Second, it increased available income for those mothers who stayed at home for at least 6 months before and after the reform by 750 Deutschmarks (1,190 Deutschmarks in 1992 prices) per month. The second effect is larger than the first effect, leading to an overall increase in available income.
} 
Panel A. Low-skilled

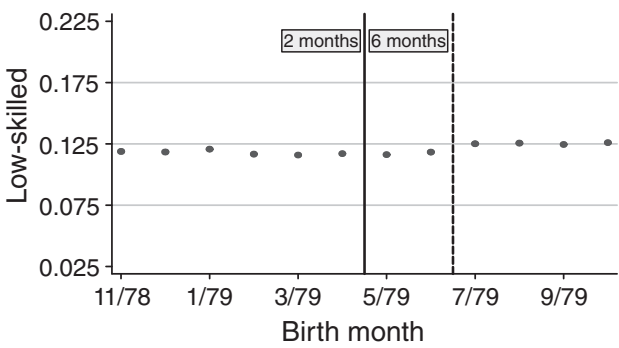

Panel C. High-skilled

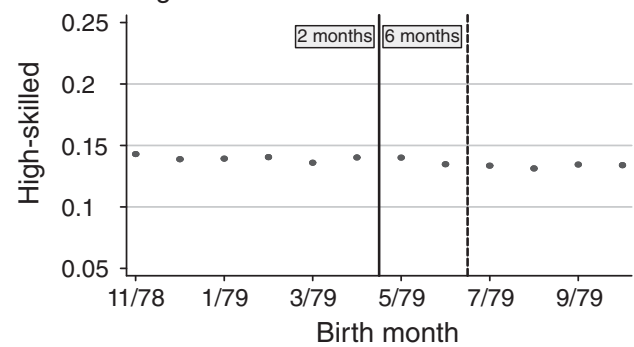

Panel E. Log wages

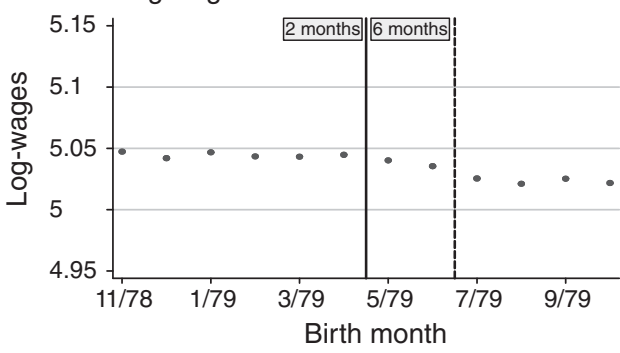

Panel B. Medium-skilled

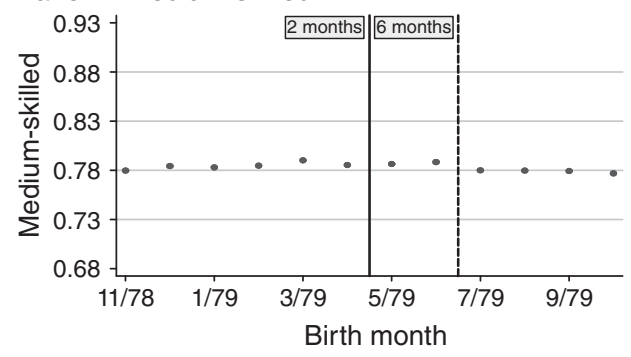

Panel D. Years of education

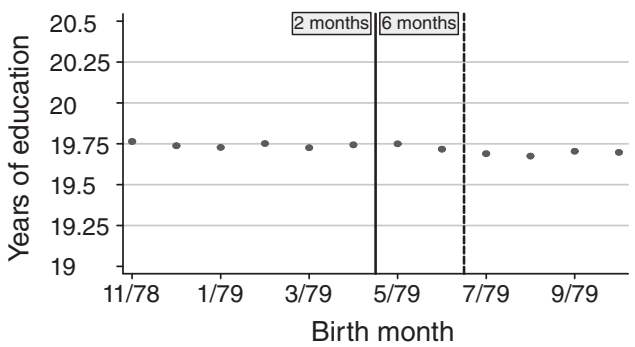

Panel F. Full-time employment

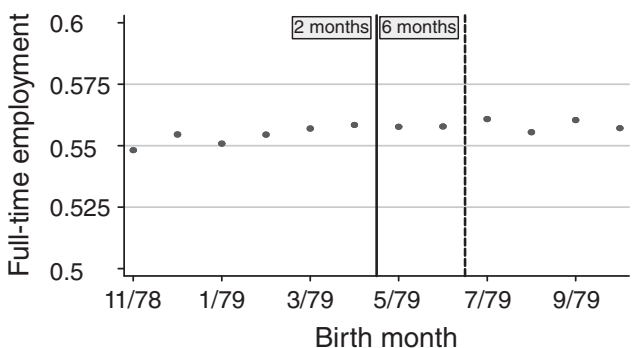

Figure 4. The Impact of the Expansion in Leave Coverage From Two to Six Months on Children's Outcomes (May 1979)

Notes: The figures plot the share of individuals without post-secondary education ("low-skilled," panel A), the share of individuals who completed an apprenticeship or equivalent ("medium-skilled," panel B), the share of individuals with a four-year college or five-year university degree ("high-skilled," panel C), the average years of education, imputed from five educational categories (panel D), the average log wage of individuals working full time (panel E), and the share of individuals who work full time (panel F) for individuals born six months before or six months after the 1979 expansion in leave coverage from two to six months. Outcomes refer to age 29. The solid vertical line indicates the expansion in leave coverage (April versus May), while the dashed vertical line indicates the age of school entry cut-off date (June versus July).

Source: Social Security Records for individuals born between November 1978 to October 1979.

income available to mothers after childbirth, the expansion in unpaid leave coverage from 18 to 36 months lead to a lower income available to mothers.

\section{B. Expansions in Leave Coverage and Children's Long-Run Outcomes (Intention-to-Treat)}

Next, we turn to the impact of the expansions in leave coverage on children's long-term outcomes. We show our results separately by policy reform, and begin 
with the first expansion in leave coverage: the increase in job-protected leave from two to six months in May 1979.

The Expansion in Leave Coverage from Two to Six Months (May 1979).-We begin with a graphical analysis. In Figure 4, we plot the share of individuals with low (panel A), medium (panel B), and high (panel C) levels of education, for individuals born within six months of the policy reform, i.e., between November 1978 and October 1979. In panels D and E, we display the average years of schooling of those individuals, and the average log wage of individuals who are employed fulltime, while we show the share of individuals who are working full time in panel $\mathrm{F}$. Outcomes refer to age 29. In each panel, the solid vertical line indicates the expansion in leave coverage from two to six months, while the dashed vertical lines indicate the age-of-school-entry cut-off dates (June versus July). Overall, the figure provides little support for the hypothesis that the expansion in leave coverage from two to six months had a positive impact on individual's educational choices or labor market outcomes. ${ }^{20}$

We investigate this further in Table 3 where we report several difference-in-difference estimates of the impact of the expansion in leave coverage on children's educational choices and labor market outcomes $\left(\alpha_{3}\right.$ in equation (2)). We begin by comparing individuals born one month before the expansion in leave coverage, i.e., in April 1979, with those born one month after the expansion, i.e., in May 1979 (row 1). We then successively increase the sample by extending the window before and after the reform to improve the precision of our estimates. In row 5, we also report estimates where we exclude individuals born one month before or after the reform. This provides an additional robustness check that our estimates are not affected by the endogenous timing of births as a response to the expansion in leave coverage (see Section II). Moreover, excluding individuals born in April or May also helps to deal with the measurement error in the child's birth month in our data on mothers (see Section IIIC). As in the previous section on maternal employment, we use individuals born in the same months, but up to two years before or one year after the expansion (i.e., individuals born in April or May 1977, 1978, or 1980 in our most stringent specification in row 1) as our control group. Our results are similar and not statistically different from each other if we use each birth cohort separately as our control group. We report heteroskedasticity-robust standard errors in parentheses. ${ }^{21}$

Table 3 confirms the visual impression of Figure 4 that the expansion in leave coverage had little impact on children's outcomes. All point estimates are small in magnitude and not statistically different from zero. The point estimates for the

\footnotetext{
${ }^{20}$ Note, however, that for wages (panel E), there is evidence for a discontinuity at the age of school entry cutoff. This is because individuals born in July enter the labor market later than individuals born in June and thus have accumulated less labor market experience.

${ }^{21}$ Although we do not see a plausible reason why there should be common group errors by birth month in our difference-in-difference estimates, we have nevertheless computed standard errors clustered by birth month. These are similar to the heteroskedasticity-robust standard errors reported here. As inference based on asymptotics is invalid due to the few number of clusters (see Donald and Lang 2007), we implement a further check and, following Cameron, Gelbach, and Miller (2008), bootstrap standard errors using a residual or wild bootstrap. The $p$-values obtained from the wild bootstrap are only slightly larger than those based on heteroskedasticity-robust standard errors. Results are available in the online Appendix on our web page. http://www.homepages.ucl.ac.uk/ uctpusc/ publications/OnlineAppendix_AmericanJournal.pdf We are grateful to Colin Cameron and Doug Miller to make their programs available to us.
} 
Table 3-The Impact of the 1979 Expansion in Leave Coverage from Two to Six Months on Children's Outcomes, DifFerence-IN-DifFEREnCE Estimates

\begin{tabular}{|c|c|c|c|c|c|c|c|}
\hline & & Low & Medium & High & $\begin{array}{c}\text { Years of } \\
\text { education }\end{array}$ & Wages & $\begin{array}{c}\text { Full-time } \\
\text { employment }\end{array}$ \\
\hline (1) & $\begin{array}{l}\text { April-May } \\
N=377,183\end{array}$ & $\begin{array}{c}-0.0012 \\
(0.0024)\end{array}$ & $\begin{array}{c}0.0006 \\
(0.0030)\end{array}$ & $\begin{array}{c}0.0000 \\
(0.0024)\end{array}$ & $\begin{array}{c}0.0099 \\
(0.0170)\end{array}$ & $\begin{array}{r}-0.0036 \\
(0.0039)\end{array}$ & $\begin{array}{c}-0.0015 \\
(0.0037)\end{array}$ \\
\hline (2) & $\begin{array}{l}\text { March-June } \\
N=752,481\end{array}$ & $\begin{array}{c}-0.0003 \\
(0.0017)\end{array}$ & $\begin{array}{c}-0.0003 \\
(0.0021)\end{array}$ & $\begin{array}{c}0.0005 \\
(0.0017)\end{array}$ & $\begin{array}{c}0.0103 \\
(0.0120)\end{array}$ & $\begin{array}{c}-0.0024 \\
(0.0027)\end{array}$ & $\begin{array}{c}-0.0003 \\
(0.0028)\end{array}$ \\
\hline (3) & $\begin{array}{l}\text { January-June } \\
N=1,108,879\end{array}$ & $\begin{array}{c}0.0003 \\
(0.0015)\end{array}$ & $\begin{array}{c}0.0001 \\
(0.0019)\end{array}$ & $\begin{array}{r}-0.0006 \\
(0.0015)\end{array}$ & $\begin{array}{c}0.0014 \\
(0.0104)\end{array}$ & $\begin{array}{r}-0.0042 \\
(0.0024)\end{array}$ & $\begin{array}{c}0.0004 \\
(0.0024)\end{array}$ \\
\hline (4) & $\begin{array}{l}\text { November-October } \\
N=2,186,358\end{array}$ & $\begin{array}{c}0.0001 \\
(0.0010)\end{array}$ & $\begin{array}{r}-0.0009 \\
(0.0013)\end{array}$ & $\begin{array}{c}0.0007 \\
(0.0010)\end{array}$ & $\begin{array}{c}0.0051 \\
(0.0070)\end{array}$ & $\begin{array}{c}-0.0007 \\
(0.0016)\end{array}$ & $\begin{array}{c}0.0022 \\
(0.0016)\end{array}$ \\
\hline (5) & $\begin{array}{l}\text { November-October, } \\
\text { excl. April and May } \\
N=1,809,175\end{array}$ & $\begin{array}{c}0.0003 \\
(0.0011)\end{array}$ & $\begin{array}{r}-0.0013 \\
(0.0014)\end{array}$ & $\begin{array}{c}0.0008 \\
(0.0011)\end{array}$ & $\begin{array}{c}0.0041 \\
(0.0077)\end{array}$ & $\begin{array}{r}-0.0000 \\
(0.0018)\end{array}$ & $\begin{array}{c}0.0031 \\
(0.0018)\end{array}$ \\
\hline
\end{tabular}

Notes: The table reports various difference-in-difference estimates of the impact of the 1979 expansion in leave coverage from two to six months on the probability of having no post-secondary education (low), the probability of completing an apprenticeship or equivalent (medium), the probability of graduating from college or university (high), the average years of education (imputed from five educational categories), the log wage of full time employees, and the probability of working full time. Outcomes refer to age 28. The control group consists of children born in the same birth months, but two years before or one year after the reform in maternity leave legislation (i.e., of individuals born between November 1976 and October 1977, November 1977 and October 1978, and November 1979 and October 1980 in specification (4)). Robust standard errors in parentheses.

*** Significant at the 1 percent level.

**Significant at the 5 percent level.

* Significant at the 10 percent level.

Source: Social Security Records for men and women born between November 1976 and October 1980.

share of low-skilled individuals range from (neg.) 0.12 percentage points in row 1 to (pos.) 0.03 percentage points in rows 3 and 5, while the point estimates for the share of high-skilled individuals vary from (neg.) 0.06 percentage points in row 3 to (pos.) 0.08 percentage points in row 5. A similar picture emerges for the average years of schooling, where our point estimates suggest that the reform increased the average education between 0.5 (row 3, $0.0014 \cdot 365)$ and 3.8 (row 2, $0.0103 \cdot 365$ ) days. Turning to wages, our point estimates compass -0.4 percent and -0.00 percent. Using specification (5) as our baseline specification, we are able to rule out the hypothesis that the expansion in leave coverage from two to six months lowered the share of low-skilled individuals by more than 0.2 percentage points, increased the share of high-skilled individuals by more than 0.26 percentage points, increased the average years of schooling by more than six days, and increased wages by more than 0.3 percent. Notice that these numbers refer to the one-sided hypothesis test $H_{0}: \hat{\beta}_{2->6}^{I T T}>0$, which is the appropriate test since an important goal of this reform was to foster child development.

The Expansion in Leave Coverage from Six to Ten Months (January 1986).Turning to the expansion in leave coverage from 6 to 10 months, we display in Figure 5 the share of individuals who graduated from the high track at age 19 or 20, for individuals born 6 months before or after the policy reform (i.e., between July 1985 and June 1986). The vertical line indicates the expansion in leave coverage. The figure provides little support for a discontinuity in the share of high track graduates around 


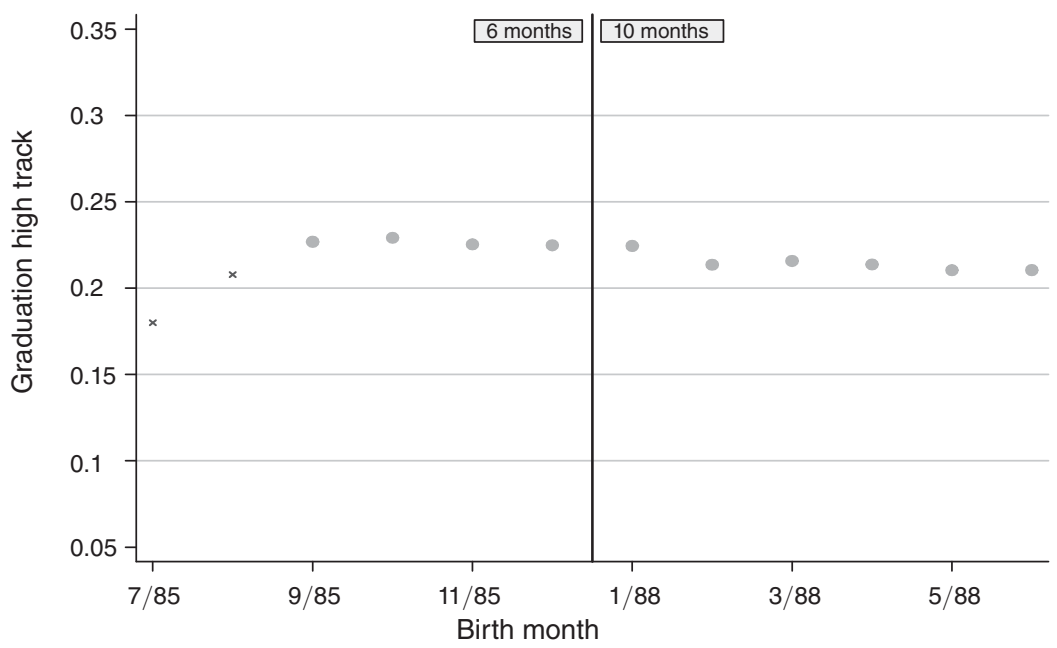

Figure 5. The Impact of the Expansion in Leave Coverage From Six to Ten Months on the Probability of Graduating from the High Track (January 1986)

Notes: The figure plots the share of individuals who graduated from the high track by age 20 for children born six months before or six months after the 1986 expansion in leave coverage from six to ten months. The vertical line indicates the expansion in leave coverage (December versus January).

Source: School Census for Bavaria, Hesse, and Schleswig-Holstein for students born between July 1985 and June 1986, combined with Natal Statistics.

Table 4-The Impact of the 1986 Expansion in Leave Coverage from Six to Ten Months on Graduation from High Track, Difference-in-Difference Estimates

\begin{tabular}{llcc}
\hline \hline & & \multicolumn{2}{c}{ Graduation High Track } \\
\cline { 2 - 3 } & & Coefficient & \multicolumn{1}{c}{ SE } \\
\hline (1) & $\begin{array}{l}\text { January-December } \\
N=97,004\end{array}$ & -0.0002 & $(0.0061)$ \\
(2) & $\begin{array}{l}\text { October-March } \\
N=289,937\end{array}$ & -0.0015 & $(0.0042)$ \\
(3) $\quad \begin{array}{l}\text { October-March (excl. January and December) } \\
N=192,933\end{array}$ & -0.0021 & $(0.0030)$ \\
(4) $\quad \begin{array}{l}\text { September-April } \\
N=391,030\end{array}$ & -0.0005 & $(0.0027)$ \\
(5) $\quad \begin{array}{l}\text { September-June } \\
N=493,997\end{array}$ & -0.0006 & $(0.0030)$ \\
(6) & $\begin{array}{l}\text { September-June (excluding January and December) } \\
N=396,993\end{array}$ & -0.0006 & \\
\hline
\end{tabular}

Notes: The table reports various difference-in-difference estimates of the impact of the 1986 expansion in leave coverage from six to ten months on the probability of graduating from the high track. The control group consists of children born in the same birth months, but one or three years after the change in leave coverage (i.e., individuals born between September 1986 and June 1987, and September 1988 and June 1989 in specification (5)). $N$ refers to the number of births. See Appendix A for the computation of standard errors.

Source: School Census for Bavaria, Hesse, and Schleswig-Holstein for pupils born between September 1985 and June 1989 combined with Natal Statistics.

the expansion in leave coverage, i.e., from December to January. Notice, however, that contrary to Figure 4, the figure reveals a moderate age-of-school-entry effect. Children born in September are about 3 percentage points more likely to graduate from the 
high track than children born in May. Moreover, the share of high track graduates is considerably lower for individuals born in July or August 1985 than for individuals born in September 1986. This is because children born in July or August often enter school a year early and hence graduate by age 18. See Appendix A for details.

In Table 4, we report various difference-in-difference estimates of the impact of the expansion in leave coverage from six to ten months on the probability that children graduate from the high track. The table has a similar structure to Table 3 . We first restrict the sample to children born in December or January, i.e., within one month of the policy reform, and then successively extend this window before and after the reform to gain precision. We do not include individuals born in July and August in our analysis since we underestimate high track graduation for these individuals - see our arguments above. Individuals born in the same birth months, but one or three years after the reform, form our control group. ${ }^{22}$ We cannot use individuals born one year before the reform as a control group due to data restrictions. We do not use individuals born 2 years after the expansion as a control group (i.e., individuals born in December 1987 and January 1988 in our most stringent specification) because there was a pre-announced expansion in leave coverage from 10 to 12 months at that time (see Section IB). See Appendix A for the computation of standard errors.

All our estimates give similar results. All point estimates are negative, small in magnitude, and not statistically different from zero, ranging from (neg.) 0.02 percentage points in row 1 to (neg.) 0.2 percentage points in row 3 . Using specification (5) that includes children born between September and June, but excludes children born in December and January, we are able to rule out the hypothesis (based on the one-sided hypothesis test $H_{0}: \hat{\beta}_{6->10}^{I T T}>0$ ) that the expansion raised graduation by more than 0.43 percentage points.

Overall, these results are not supportive of the hypothesis that the expansion in leave coverage from six to ten months improved children's educational success.

The Expansion in Leave Coverage from 18 to 36 Months (January 1992).-We now turn to the expansion in job-protected leave from 18 to 36 months, which was introduced in January 1992. In Figure 6, we plot the share of pupils who attend the low (panel A), medium (panel B), and high track (panel C) at age 14, for pupils who were born 6 months before or after the expansion in leave coverage (i.e., between July 1991 and June 1992). The vertical line indicates the expansion in leave coverage. The figure reveals a much stronger age of school entry effect than Figure $3: 23$ children born in May are about 8 percentage points less likely to attend the high track than children born in September, while, from Figure 3, the difference in the graduation rate from the high track between these children is only about 3 percentage points. This suggests that the age of school entry effect declines with age-a finding that has also been emphasized by, for instance, Mühlenweg and Puhani (2010) for Germany and by Crawford, Dearden, and Meghir (2007) for the United Kingdom.

\footnotetext{
${ }^{22}$ Our results are similar and not statistically different from each other if we use each birth cohort separately as our control group.

${ }^{23}$ Note that children born in July and August often start school a year early, and are thus younger and less likely to attend a higher track than children born in September. Similarly, children born in June often start school a year late, and are thus older and more likely to attend a higher track than children born in May.
} 
Panel A. Low track
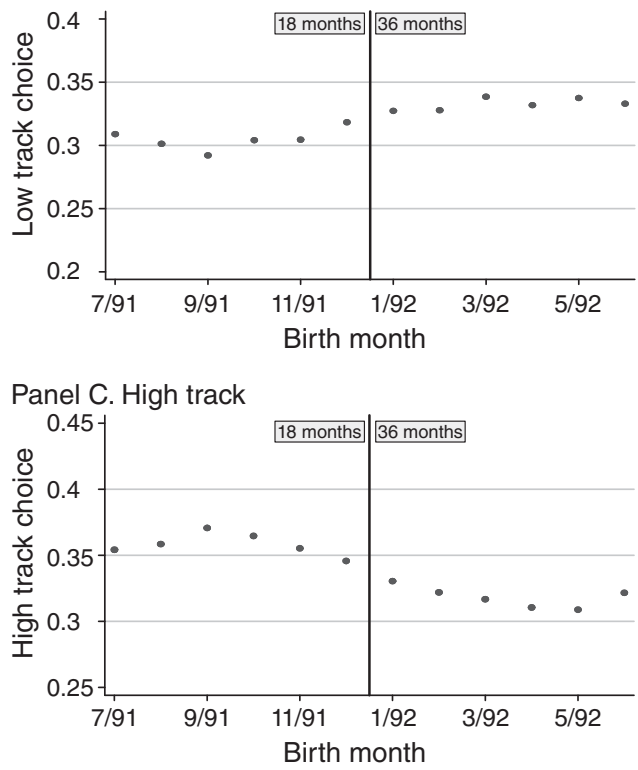

Panel B. Medium track

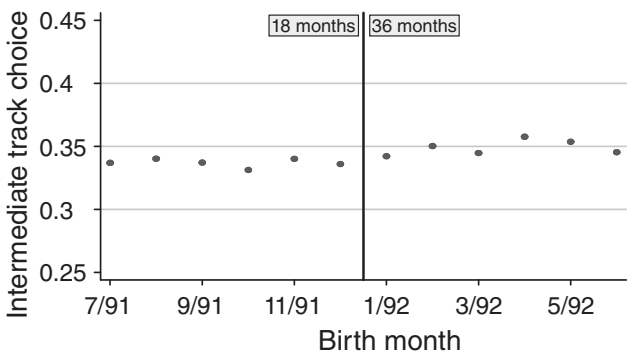

Figure 6. The Impact of the Expansion in Leave Coverage from 18 to 36 Months on Children's Track Choice (January 1992)

Notes: The figure plots the share of students attending the low- (panel A), medium- (panel B), and high-track choice (panel C) at age 14 for children born 6 months before or 6 months after the 1992 expansion in leave coverage from 18 to 36 months. The vertical line indicates the expansion in leave coverage (December versus January).

Source: School Census for Bavaria, Hesse, and Schleswig-Holstein for students born between July 1991 and June 1992.

Table 5-The Impact of the 1992 Expansion in Leave Coverage from 18 to 36 Months on Children's Track Choices, Difference in DifFerence Estimates.

\begin{tabular}{|c|c|c|c|c|c|c|c|}
\hline & & \multicolumn{2}{|c|}{ Low track } & \multicolumn{2}{|c|}{ Medium track } & \multicolumn{2}{|c|}{ High track } \\
\hline & & Coefficient & SE & Coefficient & SE & Coefficient & $\mathrm{SE}$ \\
\hline (1) & $\begin{array}{l}\text { January-December } \\
N=133,291\end{array}$ & 0.0057 & $(0.0059)$ & 0.0011 & $(0.0060)$ & -0.0068 & $(0.0060)$ \\
\hline (2) & $\begin{array}{l}\text { October-March } \\
N=396,534\end{array}$ & 0.0049 & $(0.0034)$ & 0.0011 & $(0.0035)$ & -0.0059 & $(0.0035)$ \\
\hline (3) & $\begin{array}{l}\text { October-March } \\
\text { (excl. January and December) } \\
N=263,243\end{array}$ & 0.0045 & $(0.0041)$ & 0.0011 & $(0.0042)$ & -0.0055 & $(0.0042)$ \\
\hline (4) & $\begin{array}{l}\text { September-April } \\
N=534,122\end{array}$ & 0.0056 & $(0.0029) *$ & 0.0006 & $(0.0030)$ & -0.0062 & $(0.0030) * *$ \\
\hline (5) & $\begin{array}{l}\text { July-June } \\
N=817,811\end{array}$ & 0.0045 & $(0.0024) *$ & 0.0011 & $(0.0024)$ & -0.0056 & $(0.0024) * *$ \\
\hline (6) & $\begin{array}{l}\text { July-June } \\
\text { (excl. January and December) } \\
N=684,520\end{array}$ & r) 0.0043 & $(0.0026) *$ & 0.0011 & $(0.0026)$ & -0.0054 & $(0.0026) * *$ \\
\hline
\end{tabular}

Note: The table reports various difference-in-difference estimates of the impact of the 1992 expansion in leave coverage from 18 to 36 months on children's track choice at age 14.

*** Significant at the 1 percent level.

** Significant at the 5 percent level.

* Significant at the 10 percent level.

Source: Administrative School Data for Bavaria, Hesse, and Schleswig-Holstein for pupils born between July 1990 and June 1995. 
Due to the strong age of school entry effect, no clear pattern about the effect of the expansion in leave coverage on children's track choice can be detected. In Table 5, we report difference-in-difference estimates to eliminate the age of school entry (and possible seasonal) effects. The table has the same structure as Tables 3 and 4. In our most stringent specification, we restrict the estimation sample to children born in December and January, i.e., within one month of the policy reform. We then successively increase the window before and after the reform. In order to deal with measurement error and to check the robustness of our results to the endogenous timing of births as a response to the expansion, we also report results that exclude children born one month before or after the policy reform (i.e., children born in December or January). We use children born in the same birth months, but one year before or two or three years after the policy reform (i.e., children born in December 1990, 1993, and 1994 and children born in January 1991, 1994, and 1995 in our most stringent specification in row 1) as a control group. ${ }^{24}$ We do not use children born one year after the policy reform (i.e., children born in December 1992 and January 1993) as a control group because there was a pre-announced increase in the duration during which maternity benefits are paid at that time (see Section IB). We report robust standard errors in parentheses.

All specifications lead to similar results. The expansion in leave coverage from 18 to 36 months increased the share of pupils attending the low track between 0.43 (row 5) and 0.57 (row 1) percentage points, and lowered the share of pupils attending high track schools between 0.54 (row 5) and 0.68 (row 1) percentage points. These effects are significant (at least at a 10 percent level) for specifications (4) to (6) that include children born within at least four months of the expansion. Using specification (6), and based on the one-sided hypothesis test $H_{0}: \hat{\beta}_{18->36}^{I T T}>0$, we are able to rule out the hypothesis that the expansion in leave coverage from 18 to 36 months increased high-track attendance and lowered low-track attendance at a 5 percent significance level.

Overall, these results provide no support for the hypothesis that the expansion in leave coverage from 18 to 36 months improved children's schooling outcomes. On the contrary, they suggest that the opposite may have happened, with the reform slightly lowering the fraction of children attending the high-track school, and increasing the fraction of children attending the low-track school at age 14.

Robustness Checks.-The difference-in-difference estimates in Tables 3-5 eliminate age of school entry and seasonal effects under the assumption that the seasonal and age of school entry effects are the same for the treated and the control cohorts. An alternative way of isolating the age of school entry and seasonal effect from that of the policy reform is a regression discontinuity approach that assumes a functional form for the age of school entry and seasonal effect. As a robustness check, we therefore report in the first rows of each panel in Table 6 regression discontinuity estimates of the impact of the expansions in leave coverage on children's educational

\footnotetext{
${ }^{24}$ Our results are similar and not statistically different from each other if we use each birth cohort separately as a control group.
} 
Table 6-The Impact of the EXPANSION in Leave Coverage From 18 to 36 Months on ChILdREN's Long-Term OutComes: Robustness CHECKS

(REgRession Discontinuity and Regression Discontinuity-DifFERENCE-IN-DifFerence Estimates)

\begin{tabular}{|c|c|c|c|c|c|c|c|}
\hline & & \multicolumn{6}{|c|}{ Outcomes at age 28} \\
\hline & & Low & Medium & High & $\begin{array}{l}\text { Years of } \\
\text { education }\end{array}$ & Wage & $\begin{array}{l}\text { Full-time } \\
\text { employment }\end{array}$ \\
\hline \multicolumn{8}{|c|}{ Panel A. 2 versus 6 months (May 1979) } \\
\hline (1) & $\begin{array}{l}\text { Regression discontinuity, } \\
\text { February to June }\end{array}$ & $\begin{array}{r}-0.0015 \\
(0.0028)\end{array}$ & $\begin{array}{c}0.0023 \\
(0.0034)\end{array}$ & $\begin{array}{c}-0.0003 \\
(0.0028)\end{array}$ & $\begin{array}{c}0.0112 \\
(0.0193)\end{array}$ & $\begin{array}{r}-0.0058 \\
(0.0044)\end{array}$ & $\begin{array}{r}-0.0043 \\
(0.0037)\end{array}$ \\
\hline (2) & $\begin{array}{l}\text { RD-diff-in-diff, } \\
\text { February to June }\end{array}$ & $\begin{array}{r}-0.0019 \\
(0.0032)\end{array}$ & $\begin{array}{c}0.0003 \\
(0.0039)\end{array}$ & $\begin{array}{c}0.0010 \\
(0.0032)\end{array}$ & $\begin{array}{c}0.0122 \\
(0.0220)\end{array}$ & $\begin{array}{r}-0.0026 \\
(0.0029)\end{array}$ & $\begin{array}{c}-0.0032 \\
(0.0049)\end{array}$ \\
\hline
\end{tabular}

Graduation high track by age 20

Panel B. 6 versus 10 months (January 1986)

(1) Regression discontinuity,

0.0009

October to March

$(0.0061)$

(2) RD-diff-in-diff,

$-0.0053$

October to March

$(0.0088)$

Track choice at age 14

\begin{tabular}{|c|c|c|c|}
\hline & Low & Medium & High \\
\hline \multicolumn{4}{|c|}{ Panel C. 18 versus 36 months (January 1992) } \\
\hline $\begin{array}{l}\text { (1) Regression discontinuity, } \\
\text { October to March }\end{array}$ & $\begin{array}{c}0.0032 \\
(0.0061)\end{array}$ & $\begin{array}{c}0.0046 \\
(0.0062)\end{array}$ & $\begin{array}{r}-0.0078 \\
(0.0062)\end{array}$ \\
\hline $\begin{array}{l}\text { (2) RD-diff-in-diff, } \\
\text { October to March }\end{array}$ & $\begin{array}{c}0.0065 \\
(0.0071)\end{array}$ & $\begin{array}{c}0.0008 \\
(0.0072)\end{array}$ & $\begin{array}{r}-0.0073 \\
(0.0072)\end{array}$ \\
\hline
\end{tabular}

Notes: The table reports as a robustness check regression discontinuity (row 1) and regression discontinuity-difference-in-difference estimates (row 2) of the impact of the expansions in leave coverage on children's long-term outcomes, assuming a linear age of school entry and seasonal effect. For the 1979 expansion in leave coverage from two to six months in panel A, we restrict the sample to individuals born three months before or two months after the policy reform (February to June). For the latter expansions in leave coverage from 6 to 10 months in panel B and from 18 to 36 months in panel C, the sample consists of all children born 3 months before or 3 after the policy reform (i.e., between October and March). In row 2 of each panel, the control groups are the same as those in Tables 3 to 5 (i.e., individuals born between February and June 1977, 1978, and 1980 in panel A, individuals born between October 1986 and March 1987, as well as between October 1988 and March 1989 in panel B, and individuals born between October 1990 and March 1991, between October 1993 and March 1994, as well as between October 1994 and March 1995 in panel C). Robust standard errors in parentheses.

*** Significant at the 1 percent level.

** Significant at the 5 percent level.

* Significant at the 10 percent level.

Source: Panel A: Social Security Records for men and women born between February and June 1977, 1978, 1979, or 1980. Panel B: School Census for Bavaria, Hesse, and Schleswig-Holstein for students born between October 1985 and March 1986, October 1986 and March 1987, and October 1988 and March 1989, combined with Natal Statistics. Panel C: School Census for Bavaria, Hesse, and Schleswig-Holstein for pupils born between October 1990 and March 1991, October 1991 and March 1992, October 1993 and March 1994, and October 1994 and March 1995.

outcomes. We assume that the age and seasonal effect is linear. Specifically, we estimate the following regression separately for each expansion in leave coverage:

$$
\text { Outcome }_{i, m}=\delta_{o}+\delta_{2} \text { age }_{i, m}+\delta_{3} \text { After }_{i, m}+e_{i, m},
$$

where $a g e_{i}$ measures the age (measured in months) of child $i$ born in month $m$, and After $_{i}$ is, as before, an indicator variable equal to one if the child was born after the policy reform. The coefficient of interest is $\delta_{3}$, which corresponds to $\beta_{M L}^{I T T}$ in 
equation (1) and identifies the impact of an expansion in leave coverage on child outcomes. We estimate this equation for children born within three months of the policy reform. ${ }^{25}$ The estimates in Table 6 are of similar magnitude to and not statistically different from those reported in Tables 3-5. For instance, our baseline difference-indifference estimate in Table 3, row 5, suggests that the expansion in leave coverage from 2 to 6 months increased schooling by 1.5 days $(0.0041 \cdot 365)$, compared to the regression discontinuity estimate of 4.1 days $(0.0112 \cdot 365)$. Turning to the 1992 expansion in leave coverage from 18 to 36 months, our baseline difference-in-difference estimate in Table 5, row (6), indicates that the expansion decreased high-track attendance by 0.54 percentage points, compared to the regression discontinuity estimate of 0.78 percentage points. ${ }^{26}$

In the second row of each panel in Table 6, we combine the regression discontinuity approach with the difference-in-difference approach. Like the regression discontinuity regression (3), this specification assumes a linear age of school entry and seasonal effect. However, unlike our baseline difference-in-difference regression (2), it allows this effect to differ between the treatment and control group. We estimate the following equation separately for each expansion in leave coverage:

$$
\begin{aligned}
\text { Outcome }_{i, m}= & \eta_{o}+\eta_{2} \text { age }_{i, m}+\eta_{3} \text { After }_{i, m}+\eta_{4} \text { Treat }_{i, m} \\
& +\eta_{5} \text { age }_{i, m} \cdot \text { Treat }_{i, m}+\eta_{6} \text { After }_{i, m} \cdot \text { Treat }_{i, m}+\epsilon_{i, m},
\end{aligned}
$$

where $a_{g} e_{i, m} \cdot$ Treat $_{i, m}$ is the interaction between the age of child $i$ born in month $m$, measured in months, and an indicator variable equal to one if the child belongs to the treated cohort. All other variables are defined as before. The impact of the expansion in leave coverage on children's outcomes is given by $\eta_{6}$, the difference in the discontinuous jump in education outcomes for children born shortly before or after the expansion $\left(\delta_{3}\right.$ in equation $\left.(3)\right)$ between the control and the treated cohorts. For each expansion, we use the same control cohorts as in Tables 2-5. Results are similar to and not statistically different from those reported in the first rows. Moreover, we are never able to reject the hypothesis that the age of school entry or seasonal effect is different for the treated than for the control cohorts (i.e., we fail to reject $H_{0}: \eta_{5}=0$ ), lending support to the assumption behind the difference-in-difference approach that these effects are the same for the treatment and control cohorts.

To summarize, while the 1979 and 1986 reforms in leave coverage had little impact on children's educational attainment, the 1992 expansion in leave coverage may even have lowered children's educational success. There are two main differences between the 1992 expansion in leave coverage and the earlier reforms that help explain the negative impact of the 1992 reform on child outcomes.

\footnotetext{
${ }^{25}$ For the 1979 reform, we restrict the sample to pupils born three months before or two months after the expansion (i.e., to children born between February and June 1979), as children born in July are likely to have started school a year later than children born in June.

${ }^{26}$ Our estimates hardly change if we additionally include an interaction term between age $_{i, m}$ and $A f t e r_{i, m}$ in equation (3) to allow for a different linear age trend before and after the reform.
} 
First, unlike the earlier reforms, this reform was unpaid and led to a reduction in available income of 3,092 Deutschmarks (see Table 2) which, as several studies suggest, is likely to be detrimental for child development. ${ }^{27}$ A second important difference is that the reduction in maternal employment predominantly for the 1992 reform occurred during the second and third year of the child's life, rather than during the first year when, as several studies suggest, children may benefit from alternative child care arrangements. ${ }^{28}$

\section{Discussion: TS-2SLS Estimates of Early Maternal Employment on Child Development}

Did the 1979 and 1986 expansion in leave coverage fail to improve children's outcomes simply because their impact on mothers' employment after childbirth was too small, or because the impact of early maternal employment on children's outcomes is small? We conclude our discussion with a calculation of two sample-two stage least squares (TS-2SLS) estimates of the impact of spending one additional month away from work after childbirth on children's outcomes, which we obtain by dividing the intention-to-treat estimates by the impact of the expansions in leave coverage on the number of months worked in the first 40 months since childbirth. The causal interpretation of this parameter requires an additional assumption that is not needed for a causal interpretation of the intention-to-treat effects. The expansions in leave coverage affect time investments by the mother and alternative care givers, purchases for child goods, and other factors that affect child development only through the reduction in maternal employment after childbirth. In particular, this exclusion restriction rules out that the expansions in leave coverage affected the mother's subsequent fertility behavior and thus child development. While this assumption is reasonable for the 1979 and 1986 reforms, which extended leave coverage within the first year of the child's life, it may be violated for the 1992 reform, which extended in leave coverage beyond the child's first year.

If this exclusion restriction holds, and under the standard monotonicity assumption, the TS-2SLS estimates identify a weighted average of local average treatment effects, or an "average causal response" (see e.g., Angrist and Pischke 2009). As we explain in detail in Appendix B, the TS-2SLS estimates based on the 1979 and 1986 expansion in leave coverage are primarily informative about spending one additional month away from work when the child is between two and six, and between six and ten months old, respectively, while the TS-2SLS estimate based on the 1992 expansion in leave coverage primarily speaks to the effect of

\footnotetext{
${ }^{27}$ See e.g., Dahl and Lochner (forthcoming); Morris, Duncan, and Rodrigues (2006); and Clark-Kaufmann, Duncan, and Morris (2003).

${ }^{28}$ For instance, using a longitudinal approach that follows children over an 8 year period, Broberg et al. (1997) find that children that were assigned to public child care when they were between 12 and 24 months old performed better in cognitive achievement tests at age 8 than children under exclusive paternal care. Similar findings are reported by Loeb et al. (2007) who conclude that relative to exclusive maternal supervision, center-based day care raises cognitive achievement, in particular for children who start day care around the age of 2. Magnuson, Ruhm, and Waldfogel(2007) reach a similar conclusion.
} 
Table 7-Two-Sample Two Stage Least Squares Estimates of the Impact of Early Maternal Employment on Children's Long-Term Educational Outcomes

Panel A. 2 versus 6 months (May 1979)

(1) Intention-to-treat

\begin{tabular}{cccccc} 
Low & Medium & High & $\begin{array}{c}\text { Years of } \\
\text { education }\end{array}$ & Wage & $\begin{array}{c}\text { Full-time } \\
\text { employment }\end{array}$ \\
\hline 0.0003 & -0.0013 & 0.0008 & 0.0041 & 0.0000 & 0.0031 \\
$(0.0011)$ & $(0.0014)$ & $(0.0011)$ & $(0.0077)$ & $(0.0018)$ & $(0.0018)$ \\
\hline
\end{tabular}

(2) First stage

\begin{tabular}{cc}
\hline & Maternal employment \\
Mothers on leave & All mothers \\
\hline 0.835 & 0.377 \\
$(0.093)^{* * *}$ & $(0.042)^{* * * *}$
\end{tabular}

(3) TS-2SLS

\begin{tabular}{cccccc} 
Low & Medium & High & $\begin{array}{c}\text { Years of } \\
\text { education }\end{array}$ & Wage & $\begin{array}{c}\text { Full-time } \\
\text { employment }\end{array}$ \\
\hline 0.0009 & -0.0034 & 0.0022 & 0.0109 & -0.0001 & 0.0081 \\
$(0.0030)$ & $(0.0037)$ & $(0.0029)$ & $(0.0204)$ & $(0.0047)$ & $(0.0048)$
\end{tabular}

Panel B. 6 versus 10 months (January 1986)

(1) Intention-to-treat

$\frac{\text { Graduation from high track }}{-0.0006}$

(2) First stage Maternal employment

\begin{tabular}{|c|c|}
\hline \multirow[b]{2}{*}{ Mothers on leav } & \multirow[b]{2}{*}{ All mothers } \\
\hline & \\
\hline $\begin{array}{l}1.390 \\
(0.167)^{* * *} *\end{array}$ & $\begin{array}{l}0.626 \\
(0.075) * * *\end{array}$ \\
\hline
\end{tabular}

(3) TS-2SLS

Graduation from high track

$-0.0010$

$(0.0049)$

(Continued)

spending one additional month away from work when the child is between 18 and 36 months old.

We report results for our baseline specification 29 in Table 7, where we first display intention-to-treat estimates in row 1, and first stage and TS-2SLS estimates in rows 2 and 3. Estimates based on the 1979 (panel A) and 1986 (panel B) expansions in leave coverage on children's educational attainment are closely centered around zero, statistically insignificant, and precise enough to rule out large negative effects of early maternal employment on child development. Based on a one-sided hypothesis test (which we consider as the appropriate test since the working hypothesis in the literature is that maternal employment during the child's first year is harmful to children), we can rule out the hypothesis that a reduction in maternal employment by

\footnotetext{
${ }^{29}$ The intention-to-treat estimates in the first rows correspond to specification (5) in Table 3 (1979 reform), specification (6) in Table 4 (1986 reform), and specification (6) in Table 5 (1992 reform). In the second rows, we first report the impact of the expansions in leave coverage on the number of months the mother has worked up until the child is 40 months old, for those mothers who sign up for maternity leave (see Table 2). To compute the overall impact of the expansions on overall maternal employment, we then multiply this effect with the share of mothers who sign up for maternity leave.
} 
Table 7-Two-Sample Two Stage Least Squares Estimates of the Impact of Early Maternal Employment on Children's Long-Term Educational Outcomes (Continued)

Panel C. 18 versus 36 months (January 1992)

(1) Intention-to-treat

Track choice at age 14

\begin{tabular}{ccc}
\cline { 2 - 3 } Low & Medium & High \\
\hline 0.0043 & 0.0011 & -0.0054 \\
$(0.0026) *$ & $(0.0026)$ & $(0.0026) * *$
\end{tabular}

(2) First stage

Maternal employment

\begin{tabular}{|c|c|c|}
\hline & Mothers on leave & All mothers \\
\hline & $\begin{array}{l}1.363 \\
(0.106) * * *\end{array}$ & $\begin{array}{l}0.745 \\
(0.058) * * *\end{array}$ \\
\hline
\end{tabular}

(3) TS-2SLS

Track choice at age 14

\begin{tabular}{ccc}
\cline { 2 - 3 } Low & Medium & High \\
\hline 0.0058 & 0.0015 & -0.0072 \\
$(0.0035) *$ & $(0.0035)$ & $(0.0036) * *$
\end{tabular}

Notes: In each panel, we first report intention-to-treat estimates of the expansions in leave coverage on children's outcomes (row 1, see Tables 3-5). We then display first-stage estimates of the impact of the expansions in leave coverage on the number of months the mother was employed during the first 40 months after childbirth (row 2, see Table 2). We finally report TS-2SLS estimates of the impact of working 1 month less in the first 40 months after childbirth on children's outcome, which we obtain by dividing the intention-to-treat estimates by the first-stage estimates. When reporting first-stage estimates in row 2, we first display the impact of the expansions on early maternal employment for mothers who signed up for maternity leave (see Table 2). We then multiply this number by the share of mothers who signed up for maternity leave in the year of the reform (see Figure 2) to obtain the impact of the expansions on early maternal employment for all mothers. For the 1986 (panel B) and 1992 (panel C) expansion in leave coverage, this share is computed from the IABS Plus 75-95. For the 1979 expansion in leave coverage, this share is approximated as the ratio between the number of mothers on maternity leave in the social security records and the number of births to German citizens, plus the average difference between this ratio and the share of mothers who take maternity leave in the IABS Plus 75-95 for the years 1986 to 1995 (0.082) —see Figure 2. In each panel, the estimation sample includes children (and their mothers) born 6 months before (4 months for the 1986 expansion) or 6 months after the expansion in leave coverage, and excludes children born one month before or after the expansion. This specification corresponds to those in Table 2 and those in the last rows of Tables 3-5. Standard errors are obtained using the Delta method, see Appendix B for details.

*** Significant at the 1 percent level.

** Significant at the 5 percent level.

* Significant at the 10 percent level.

Source: See Tables 2-4 and Table 7.

one month when the child is between 2 and 6 months old increases average schooling by more than 16 days, and increases wages by more than 0.8 percent (panel A). Similarly, we can reject the hypothesis that working one month less when the child is between 6 and 10 months old increases the probability of graduating from the high track by more than 0.72 percentage points (panel B). ${ }^{30}$ As regards the TS-2SLS estimates based on the 1992 expansion in leave coverage in panel C, they indicate that staying one additional month away from work when the child is between 18 and

\footnotetext{
${ }^{30}$ Note that these findings do not necessarily imply that, in the first year of the child's life, the time the child spends with alternative care givers is as valuable as the time she spends with her mother. This is because an increase in the mother's labor supply by one hour may decrease the time the child spends with her mother by less than the time the child spends with alternative care givers, as working mothers may cut back on their leisure and household work activities instead. Our own calculations based on the German Time Use Survey for the years 1990/1991 confirm this. A one-hour increase in usual hours worked leads to a reduction in the time spent on direct child care activities, such as playing, feeding, or bathing, by only 0.3 hours. Other household and leisure activities decline by roughly the same amount.
} 
36 months old increases the probability that the child attends the low track by about 0.6 percentage points, and lowers the probability that the child attends the high track by about 0.7 percentage points. This effect is statistically significant at a 10 and 5 percent level, respectively.

\section{Conclusion}

In this paper, we evaluate the impact of three major expansions in maternity leave coverage in Germany on children's long-term educational outcomes. An important goal of these reforms was to foster child development, and the reforms were explicitly aimed at increasing the time mothers spend with their children after childbirth. However, comparing educational and labor market outcomes of children born shortly before and after a reform, we find no evidence that the expansions improved children's outcomes, although they had a strong impact on mother's return to work behavior after childbirth. Given the precision of our baseline estimates, we are able to exclude the possibility that the expansion in paid leave from 2 to 6 months in 1979 increased children's average years of schooling by more than 6 days and increased wages at the age of 28 by more than 0.3 percent. We are also able to rule out the hypothesis that the expansion in paid leave from 6 to 10 months in 1986 raised the probability of completing the high track by more than 0.42 percentage points.

The expansion in unpaid leave from 18 to 36 months in 1992 may even have slightly lowered children's educational attainment. Here, our point estimates indicate that the reform increased the probability that the child attends the low track by about 0.5 percentage points, and lowered the probability that the child attends the high track by roughly the same amount. There are two main differences between the 1992 expansion in leave coverage and the earlier reforms that help explain the negative impact of the 1992 reform on child outcomes. First, while the 1979 and 1986 expansions in leave coverage slightly increased income available to mothers after childbirth, the 1992 expansion lead, in 1992 prices, to an income loss of 3,092 Deutschmarks (\$2,023 dollars, using the 1992 exchange rate), which—as several studies suggest—is likely to harm the child's development. Second, while the 1979 and 1986 expansions in leave coverage reduced maternal employment during the first year of the child's life, the 1992 expansion lowered maternal employment during the second and third year of the child's life. Our findings are consistent with the hypothesis that children older than 18 months benefit from the stimuli that care givers other than their mother provide.

Overall, our findings provide little support for the hypothesis that expansions in leave coverage improve the welfare of children. This, however, has been an important objective of similar reforms around the world.

\section{APPENDIX}

\section{A. Administrative Data on School Choices (Children)}

In order to compute the stock of pupils graduating from the high track, we add up the number of pupils who attend the thirteenth (last) grade of a high-track school in the academic school years in which they turn 19 (e.g., 2004/05 for pupils born 
between July 1985 and June 1986) and 20 (e.g., 2005/06 for pupils born between July 1985 and June 1986). This way, we allow for one extra year to finish the high track, due to e.g., grade repetition or delayed school entry. There are few pupils who are observed in thirteenth grade beyond age $20 .{ }^{31}$ We then proxy graduation from the high track as the ratio between the number of students ever observed in thirteenth grade and the number of recorded births, by birth month and state.

Note that this measure does not include pupils who graduate from the high track in the year they turn 18 (e.g., 2003/2004 for pupils born between July 1985 and June 1986). This is because our data for Bavaria starts in 2004/2005, only when pupils affected by the 1986 policy reform (i.e., pupils born between July 1985 and June 1986) turn 19. The share of pupils graduating from the high track by age 18 is small for pupils born between September and June (less than 0.5 percent in our sample), but reaches 5.3 percent and 3.4 percent for pupils born in July and August, respectively - as these pupils are more likely start school one year earlier than suggested by the age cut-off rule. This explains the lower share of high-track graduates among children born in July and August in Figure 4, and why we discard these children from our estimation sample.

Let $\hat{p}$ denote the share of pupils graduating from the high track. The standard error of this share is estimated as the square root of

$$
\operatorname{Var}(\hat{p})=\frac{\hat{p}(1-\hat{p})}{N},
$$

where $N$ refers to the number of births in each cell. The variance of the differencein-difference estimates of the impact of the expansion in leave coverage from six to ten months in Table 3 is given by:

$$
\begin{aligned}
& \operatorname{Var}\left(\left(\hat{p}_{\text {affer }}^{\text {treat }}-\hat{p}_{\text {before }}^{\text {treat }}\right)-\left(\hat{p}_{\text {affer }}^{\text {control }}-\hat{p}_{\text {before }}^{\text {control }}\right)\right)=\frac{\hat{p}_{\text {affer }}^{\text {treat }}\left(1-\hat{p}_{\text {affer }}^{\text {treat }}\right)}{N_{\text {affer }}^{\text {treat }}}+\frac{\hat{p}_{\text {before }}^{\text {treat }}\left(1-\hat{p}_{\text {before }}^{\text {treat }}\right)}{N_{\text {before }}^{\text {treat }}} \\
& +\frac{\hat{p}_{\text {after }}^{\text {control }}\left(1-\hat{p}_{\text {after }}^{\text {control }}\right)}{N_{\text {affer }}^{\text {control }}}+\frac{\hat{p}_{\text {before }}^{\text {control }}\left(1-\hat{p}_{\text {before }}^{\text {control }}\right)}{N_{\text {before }}^{\text {contro }}},
\end{aligned}
$$

where the superscripts "treat" and "control" refer to the treatment and control cohort (i.e., September 1985 to July 1986 versus September 1986 (1988) to July 1987 (1989)), and the subscripts "before" and "after" refer to whether the individual was born before or the month the leave policy was implemented (i.e., between September and December versus between January and June).

\section{B. Two Sample-Two Stage Least Squares Estimation}

To obtain TS-2SLS estimates of the impact of spending one additional month away from work in the first 40 months after childbirth on children's outcomes, we divide our intention-to-treat estimates in Tables $2-4$ by the impact of the expansions

\footnotetext{
${ }^{31}$ For those birth cohorts for which we are able to compute graduation rates by age 18 to age 22 , the graduation rates by age 20,21 , and 22 are 27.2 percent, 28.5 percent, and 28.6 percent, respectively.
} 
in leave coverage on the number of months worked since childbirth (see Table 7, column 3):

(A1) $\delta^{\mathrm{TS}-2 \mathrm{SLS}}=\frac{E\left[Y_{i}^{A} \mid M L=t_{2}\right]-E\left[Y_{i}^{A} \mid M L=t_{1}\right]}{E\left[\text { months at home }_{i}^{\text {Mother }} \mid M L=t_{2}\right]-E\left[\text { months at home }_{i}^{\text {Mother }} \mid M L=t_{1}\right]}$.

If the exclusion restriction holds, and under the standard monotonicity assumption, equation (A1) identifies a weighted average of local average treatment effects, or and "average causal response" (see e.g., Angrist and Pischke 2009):

$$
\begin{aligned}
\delta^{\mathrm{TS}-2 \mathrm{SLS}} & =\sum_{t=0}^{40} w_{t} E\left[Y_{i, t}^{A}-Y_{i, t-1}^{A} \mid t_{i, M L=t_{2}} \geq t>t_{i, M L=t_{1}}\right], \quad \text { where } \\
w_{t} & =\frac{P\left[t_{i, M L=t_{2}} \geq t>t_{i, M L=t_{1}}\right]}{\sum_{j=1}^{40} P\left[t_{i, M L=t_{2}} \geq j>t_{i, M L=t_{1}}\right]},
\end{aligned}
$$

where the subscript $t$, which runs from 0 to 40 , denotes the number of months the mother has spent away from work until her child is 40 months old. $E\left[Y_{i, t}-\right.$ $\left.Y_{i, t-1} \mid t_{i, M L=t_{2}} \geq t>t_{i, M L=t_{1}}\right]$ is the impact of spending $t$ rather than $t-1$ months away from work after childbirth on children's outcomes (measured at age $a=A$ ), for those women who spend $t$ months or more at home after childbirth if exposed to $t_{2}$ months of leave, but would spend less than $t$ months at home if exposed to $t_{1}$ months of leave. The weights are given by equation (A2), where the denominator is the first stage, i.e., the impact of the expansion in leave coverage on the number of months away from work since childbirth. The numerator measures the size of the group of compliers at point $t$, and represents the share of women who, if eligible for $t_{2}$ months of leave coverage, spend $t$ months or more at home after childbirth, but would spend less than $t$ months at home if eligible for $t_{1}$ months of leave coverage.

We plot these weights in Figure A1. For each policy reform, the weights are small prior to the end of the old maternity leave period $t_{1}$ and following the end of the new leave period $t_{2}$, and are roughly of equal size between months $t_{1}$ to $t_{2}$. Hence, the estimates based on the 1979 and 1986 expansions in leave coverage are primarily informative about working one month less during the first year of the child's life when the child is between two and six months and between six and ten months old, respectively. The estimates based on the 1992 expansion in leave coverage, in contrast, are primarily informative about working one month less during the second and third year of the child's life when the child is between 18 and 36 months old.

Since we obtain the intention-to-treat and first-stage estimates from two different samples, we compute standard errors using the Delta method. We obtain

$$
\widehat{\operatorname{Var}}\left[\hat{\beta}_{t_{1}->t_{2}}^{\mathrm{TS}-2 S L S}\right]=\left[\left(\hat{\alpha}_{3}^{t_{1}->t_{2}}\right)^{2} \widehat{\operatorname{Var}}\left(\hat{\gamma}_{3}^{t_{1}->t_{2}}\right)+\left(\hat{\gamma}_{3}^{t_{1}->t_{2}}\right)^{2} \widehat{\operatorname{Var}}\left(\hat{\alpha}_{3}^{t_{1}->t_{2}}\right)\right] /\left[\left(\hat{\gamma}_{3}^{t_{1}->t_{2}}\right)^{4}\right],
$$

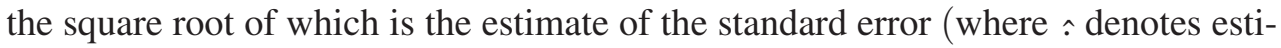
mates). See Dee and Evans (2003) for a similar approach in an exactly identified TS-2SLS application. 
Panel A. Expansion from 2 to 6 months

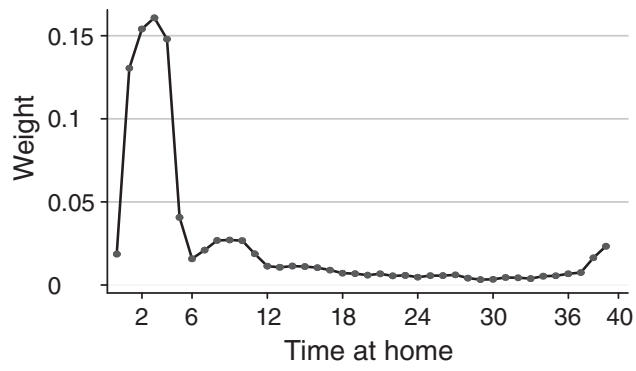

Panel A. Expansion from 2 to 6 months

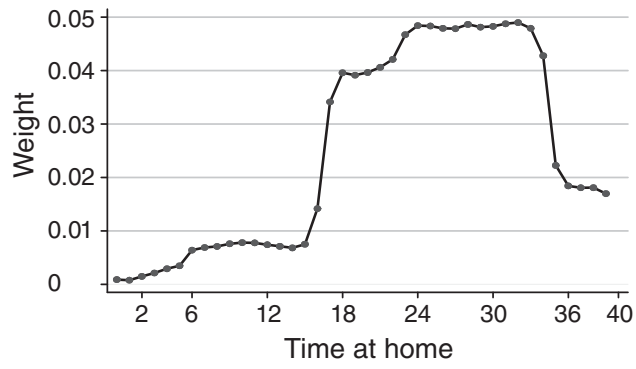

Panel B. Expansion from 6 to 10 months

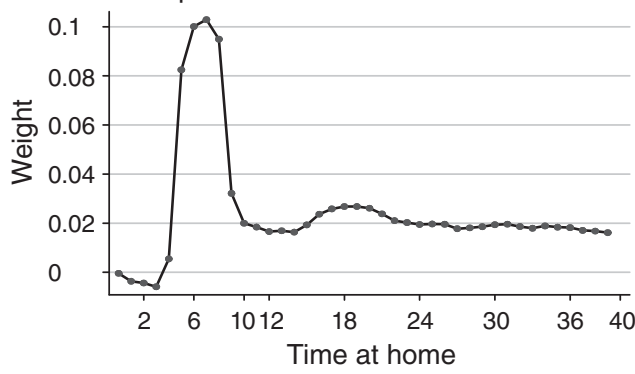

Figure A1. Weights Given to Local Average Treatment Effects (Equation (A2))

Note: The figures plot the weights given to each local average treatment effect in the average causal response (equation (A2) in the Appendix).

Source: Social Security Records on women who give birth and sign up for maternity leave between November 1976 and October 1980 (panel A), between September 1985 and June 1989 (panel B), and between July 1990 and June 1995 (panel C).

\section{REFERENCES}

Angrist, Joshua D., and Alan B. Krueger. 1992. "The Effect of Age at School Entry on Educational Attainment: An Application of Instrumental Variables with Moments from Two Samples.” Journal of the American Statistical Association 87 (418): 328-36.

Angrist, Joshua D., and Jorn-Steffen Pischke. 2009. Mostly Harmless Econometrics: An Empiricist's Companion. Princeton: Princeton University Press.

- Baker, Michael, Jonathan Gruber, and Kevin Milligan. 2008. "Universal Child Care, Maternal Labor Supply, and Family Well-Being." Journal of Political Economy 116 (4): 709-45.

Baker, Michael, and Kevin Milligan. 2008. "Maternal Employment, Breastfeeding, and Health: Evidence from Maternity Leave Mandates." Journal of Health Economics 27 (4): 871-87.

- Baker, Michael, and Kevin Milligan. 2010. "Evidence from Maternity Leave Expansions of the Impact of Maternal Care on Early Child Development." Journal of Human Resources 45 (1): 1-32.

- Barrow, Lisa. 1999. "An Analysis of Women's Return-to-Work Decisions Following First Birth." Economic Inquiry 37 (3): 432-51.

- Baum, Charles L., II. 2003. "Does Early Maternal Employment Harm Child Development? An Analysis of the Potential Benefits of Leave Taking." Journal of Labor Economics 21 (2): 409-48.

- Baydar, Nazli, and Jeanne Brooks-Gunn. 1991. "Effects of Maternal Employment and Child-Care Arrangements on Preschoolers' Cognitive and Behavioral Outcomes: Evidence from the Children of the National Longitudinal Survey of Youth.” Developmental Psychology 27 (6): 932-45.

- Bedard, Kelly, and Elizabeth Dhuey. 2006. "The Persistence of Early Childhood Maturity: International Evidence of Long-Run Age Effects." Quarterly Journal of Economics 121 (4): 1437-72.

- Belsky, Jay. 1988. “The 'Effects' of Infant Day Care Reconsidered.” Early Childhood Research Quarterly 3 (3): 235-72. 
Belsky, Jay, and David Eggebeen. 1991. "Early and Extensive Maternal Employment and Young Children's Socioemotional Development: Children of the National Longitudinal Survey of Youth." Journal of Marriage and the Family 53 (4): 1083-98.

Berger, Lawrence M., Jennifer Hill, and Jane Waldfogel. 2005. "Maternity Leave, Early Maternal Employment and Child Health and Development in the US." Economic Journal 115 (501): F29-47.

Bernal, Raquel. 2008. "The Effect of Maternal Employment and Child Care on Children's Cognitive Development." International Economic Review 49 (4): 1173-1209.

Bernal, Raquel, and Michael P. Keane. 2010. "Quasi-structural Estimation of a Model of Childcare Choices and Child Cognitive Ability Production.” Journal of Econometrics 156 (1): 164-89.

Bowlby, John. 1969. Attachment and Loss. New York: Basic Books.

Broberg, Anders G., Holger Wessels, Michael E. Lamb, and C. Philip Hwang. 1997. "Effects of Day Care on the Development of Cognitive Abilities in 8-Year-Olds: A Longitudinal Study." Developmental Psychology 33 (1): 62-69.

Brooks-Gunn, Jeanne, Wen-Jui Han, and Jane Waldfogel. 2002. "Maternal Employment and Child Cognitive Outcomes in the First Three Years of Life: The NICHD Study of Early Child Care." Child Development 73 (4): 1052-72.

Buckles, Kasey, and Daniel M. Hungerman. 2008. "Season of Birth and Later Outcomes: Old Questions, New Answers." National Bureau of Economic Research (NBER) Working Paper 14573.

Bundesagentur für Arbeit. 2004. "Arbeitsmarkt 2003." Amtliche Nachrichten der Bundesagentur für Arbeit.

Cameron, A. Colin, Jonah B. Gelbach, and Douglas L. Miller. 2008. "Bootstrap-Based Improvements for Inference with Clustered Errors." Review of Economics and Statistics 90 (3): 414-27.

Carneiro, Pedro, Katrine Løken, and Kjell G. Salvanes. 2011. "A Flying Start? Maternity Leave Benefits and Long Run Outcomes of Children.” IZA Discussion Paper 5793.

Clark-Kauffman, Elizabeth, Greg J. Duncan, and Pamela Morris. 2003. "How Welfare Policies Affect Child and Adolescent Achievement." American Economic Review 93 (2): 299-303.

Crawford, Claire, Lorraine Dearden, and Costas Meghir. 2007. "When You Are Born Matters: The Impact of Date of Birth on Child Cognitive Outcomes in England." Centre for the Economics of Education (CEE) Discussion Paper 0093.

Currie, Janet, and Duncan Thomas. 1995. "Does Head Start Make a Difference?" American Economic Review 85 (3): 341-64.

Currie, Janet, and Duncan Thomas. 1999. “Does Head Start Help Hispanic Children?” Journal of Public Economics 74 (2): 235-62.

Dahl, Gordon, and Lance Lochner. Forthcoming. "The Impact of Family Income on Child Achievement: Evidence from the Earned Income Tax Credit." American Economic Review.

Dee, Thomas S., and William N. Evans. 2003. "Teen Drinking and Educational Attainment: Evidence from Two-Sample Instrumental Variables Estimates.” Journal of Labor Economics 21 (1): 178-209.

Dickert-Conlin, Stacy, and Amitabh Chandra. 1999. "Taxes and the Timing of Births." Journal of Political Economy 107 (1): 161-77.

Donald, Stephen G., and Kevin Lang. 2007. "Inference with Difference-in-Differences and Other Panel Data." Review of Economics and Statistics 89 (2): 221-33.

Dustmann, Christian. 2004. "Parental Background, Secondary School Track Choice, and Wages." Oxford Economic Papers 56 (2): 209-30.

Dustmann, Christian, and Uta Schönberg. 2012. "Expansions in Maternity Leave Coverage and Children's Long-Term Outcomes: Dataset." American Economic Journal: Applied Economics. http:// dx.doi.org/10.1257/app.4.3.190.

Ekberg, John, Rickard Eriksson, and Guido Friebel. 2005. "Parental Leave: A Policy Evaluation of the Swedish 'Daddy-Month' Reform.” Institute for the Study of Labor (IZA) Discussion Paper 1617.

Gans, Joshua S., and Andrew Leigh. 2009. "Born on the First of July: An (Un)natural Experiment in Birth Timing." Journal of Public Economics 93 (1-2): 246-63.

Garces, Eliana, Duncan Thomas, and Janet Currie. 2002. "Longer-Term Effects of Head Start." American Economic Review 92 (4): 999-1012.

Grogger, Jeffrey, Lynn A. Karoly, and Jacob Alex Klerman. 2002. "Consequences of Welfare Reform: A Research Synthesis." Santa Monica: Rand Corporation.

Gustaffson, Siv S., Cecile M. M. P. Wetzels, Jan Dirk Vlasblom, and Shirley Dex. 1996. "Women's Labor Force Transitions in Connection with Childbirth: A Panel Data Comparison between Germany, Sweden, and Great Britain." Journal of Population Economics 9 (3): 223-46.

Harris, Paul L. 1983. "Infant Cognition." In Handbook of Child Psychology, Socialization, Personality, and Social Development, 4th ed., edited by Paul H. Mussen, 689-782. New York: Wiley \& Sons. 
Hickl, E. J., and H. Franzki. 2002. "Indikationen zur Sectio caesarea-Zur Frage der sog. Sectio auf Wunsch.” Der Gynäkologe 35 (2): 197-202.

Ip, Stanley, Mei Chung, Gowri Raman, Priscilla Chew, Nombulelo Magula, Deirdre DeVine, Thomas Trikalinos, and Joseph Lau. 2007. "Breastfeeding and Maternal and Infant Health Outcomes in Developed Countries." US Department of Health and Human Services Agency for Healthcare Research and Quality. Evidence Report/Technology Assessment 153. Boston, April.

James-Burdumy, Susanne. 2005. "The Effect of Maternal Labor Force Participation on Child Development." Journal of Labor Economics 23 (1): 177-211.

Lalive, Rafael, Analia Schlosser, Andreas Steinhauer, and Josef Zweimüller. 2011. "Parental Leave and Mothers' Careers: The Relative Importance of Job Protection and Cash Benefits." Institute for the Study of Labor (IZA) Discussion Paper 5792.

Lalive, Rafael, and Josef Zweimüller. 2009. "How Does Parental Leave Affect Fertility and Return to Work? Evidence from Two Natural Experiments." Quarterly Journal of Economics 124 (3): 13631402.

Leibowitz, Arleen, and Jacob Alex Klerman. 1995. "Explaining Changes in Married Mothers' Employment over Time." Demography 32 (3): 365-78.

Leibowitz, Arleen, Jacob A. Klerman, and Linda Waite. 1992. "Women's Employment During Pregnancy and Following Birth.” National Longitudinal Surveys (NLS) Discussion Paper 92-11.

León-Cava, Natalia, Chessa Lutter, Jay Ross, and Luann Martin. 2002. "Quantifying the Benefits of Breastfeeding: A Summary of the Evidence." The Food and Nutrition Program, Pan American Health Organization, Washington, DC. http://www.paho.org/English/AD/FCH/BOB-Main.htm.

Lewis, Michael, and Jeanne Brooks-Gunn. 1979. Social Cognition and the Acquisition of Self. New York: Plenum.

Lindberg, Laura D. 1996. "Women's Decision about Breastfeeding and Maternal Employment." Journal of Marriage and the Family 58 (1): 239-51.

Liu, Qian, and Oskar Nordstrom Skans. 2010. “The Duration of Paid Parental Leave and Children's Scholastic Performance." B.E. Journal of Economic Analysis and Policy: Contributions to Economic Analysis and Policy 10 (1).

Loeb, Susanna, Margaret Bridges, Daphna Bassok, Bruce Fuller, and Russell W. Rumberger. 2007. "How Much Is Too Much? The Influence of Preschool Centers on Children's Social and Cognitive Development." Economics of Education Review 26 (1): 52-66.

Magnuson, Katherine A., Christopher Ruhm, and Jane Waldfogel. 2007. "Does Prekindergarten Improve School Preparation and Performance?" Economics of Education Review 26 (1): 33-51.

Morris, Pamela, Greg J. Duncan, and Christopher Rodrigues. 2006. "Does Money Really Matter? Estimating Impacts of Family Income on Young Children's Achievement with Data from RandomAssignment Experiments." Unpublished.

Mühlenweg, Andrea M., and Patrick A. Puhani. 2010. "The Evolution of the School-Entry Age Effect in a School Tracking System." Journal of Human Resources 45 (2): 407-38.

Murnane, Richard J., Rebecca A. Maynard, and James C. Ohls. 1981. "Home Resources and Children's Achievement." Review of Economics and Statistics 63 (3): 369-77.

Phipps, Shelley A., and Peter S. Burton. 1998. "What's Mine Is Yours? The Influence of Male and Female Incomes on Patterns of Household Expenditure.” Economica 65 (260): 599-613.

Rossin, Maya. 2011. "The Effects of Maternity Leave on Children's Birth and Infant Health Outcomes in the United States." Journal of Health Economics 30 (2): 221-39.

Ruhm, Christopher J. 2000. "Parental Leave and Child Health." Journal of Health Economics 19 (6): 931-60.

Schönberg, Uta. 2009. "Does the IABS Reliably Identify Maternity Leave Taking? A Data Report." Journal for Labor Market Research 42 (1): 49-70.

Schönberg, Uta, and Johannes Ludsteck. 2011. "Expansions in Maternity Leave Coverage and Mother's Labor Market Outcomes after Childbirth." Unpublished.

Smolensky, Eugene, and Jennifer A. Gootman. 2003. "Working Families and Growing Kids: Caring for Children and Adolescents." Washington, DC: National Academies Press.

Tanaka, Sakiko. 2005. "Parental Leave and Child Health across OECD Countries." Economic Journal 115 (501): F7-28.

Vaskovics, Laszlo A., and Harald Rost. 1999. "Väter und Erziehungsurlaub." Stuttgart: Bundesministerium für Familie, Senioren, Frauen und Jugend.

Würtz Rasmussen, Astrid. 2010. "Increasing the Length of Parents' Birth-Related Leave: The Effect on Children's Long-Term Educational Outcomes." Labour Economics 17 (1): 91-100. 


\section{This article has been cited by:}

1. Edwin Ng, Mireia Julià, Carles Muntaner, Patricia O'Campo. 2017. Family support policies and child outcomes: a realist-scoping review. Community, Work \& Family 20:3, 292-306. [Crossref]

2. Louise Voldby Beuchert, Maria Knoth Humlum, Rune Vejlin. 2016. The length of maternity leave and family health. Labour Economics 43, 55-71. [Crossref]

3. Gordon B. Dahl, Katrine V. Løken, Magne Mogstad, Kari Vea Salvanes. 2016. What Is the Case for Paid Maternity Leave?. Review of Economics and Statistics 98:4, 655-670. [Crossref]

4. Emilia Del Bono, Marco Francesconi, Yvonne Kelly, Amanda Sacker. 2016. Early Maternal Time Investment and Early Child Outcomes. The Economic Journal 126:596, F96-F135. [Crossref]

5. Adam Burtle, Stephen Bezruchka. 2016. Population Health and Paid Parental Leave: What the United States Can Learn from Two Decades of Research. Healthcare 4:2, 30. [Crossref]

6. Bernd Fitzenberger, Susanne Steffes, Anthony Strittmatter. 2016. Return-to-job during and after parental leave. The International Journal of Human Resource Management 27:8, 803-831. [Crossref]

7. Janet Currie. 2016. How Can We Reduce Child Poverty and Support Parental Employment?. Academic Pediatrics 16:3, S13-S15. [Crossref]

8. Timo Hener. 2016. Unconditional Child Benefits, Mothers' Labor Supply, and Family WellBeing: Evidence from a Policy Reform. CESifo Economic Studies ifw007. [Crossref]

9. Martha H. Stinson, Peter Gottschalk. Is There an Advantage to Working? The Relationship between Maternal Employment and Intergenerational Mobility 355-405. [Crossref]

10. D. Figlio, K. Karbownik, K.G. Salvanes. Education Research and Administrative Data 75-138. [Crossref]

11. Kamila Cygan-Rehm. 2016. Parental leave benefit and differential fertility responses: evidence from a German reform. Journal of Population Economics 29:1, 73-103. [Crossref]

12. Rasheda Khanam, Hong Son Nghiem, Luke Connelly. 2015. The effects of parental leave on child health and postnatal care: Evidence from Australia. Economic Analysis and Policy . [Crossref]

13. Michael Baker, Kevin Milligan. 2015. Maternity leave and children's cognitive and behavioral development. Journal of Population Economics 28:2, 373-391. [Crossref]

14. Christina Felfe, Natalia Nollenberger, Núria Rodríguez-Planas. 2015. Can't buy mommy's love? Universal childcare and children's long-term cognitive development. Journal of Population Economics 28:2, 393-422. [Crossref]

15. Uta Schönberg, Johannes Ludsteck. 2014. Expansions in Maternity Leave Coverage and Mothers' Labor Market Outcomes after Childbirth. Journal of Labor Economics 32:3, 469-505. [Crossref]

16. Eric Bettinger, Torbjørn Hægeland, Mari Rege. 2014. Home with Mom: The Effects of Stayat-Home Parents on Children's Long-Run Educational Outcomes. Journal of Labor Economics 32:3, 443-467. [Crossref]

17. Bernd Fitzenberger, Katrin Sommerfeld, Susanne Steffes. 2013. Causal effects on employment after first birth - A dynamic treatment approach. Labour Economics 25, 49-62. [Crossref]

18. Mari Rege, Ingeborg F. Solli. 2013. The Impact of Paternity Leave on Fathers' Future Earnings. Demography . [Crossref]

19. Libertad González. 2013. The Effect of a Universal Child Benefit on Conceptions, Abortions, and Early Maternal Labor Supply. American Economic Journal: Economic Policy 5:3, 160-188. [Abstract] [View PDF article] [PDF with links] 
20. Maya Rossin-Slater, Christopher J. Ruhm, Jane Waldfogel. 2013. The Effects of California's Paid Family Leave Program on Mothers' Leave-Taking and Subsequent Labor Market Outcomes. Journal of Policy Analysis and Management 32:2, 224-245. [Crossref]

21. Omar Faroque, Md. Rafiqul Islam, Md. Obaidur Rahman, Md. Mominul Islam. 2013. Maternity Benefit Practices at NGOs in Bangladesh: Laws and Implementation. Beijing Law Review 04:04, 168-173. [Crossref] 